\title{
Análisis del estado estructural y administrativo de los campos de juego de los distritos urbanos de Ulloa, San Francisco, Heredia Centro y Mercedes del Cantón Central de la provincia de Heredia
}

\author{
(Analysis of Structural and Administrative Status of \\ the Playing Grounds of Urban Districts: Ulloa, San \\ Francisco, Central Heredia, and Mercedes of the Central \\ Canton, Province of Heredia)
}

\author{
María Morera Castro ${ }^{1}$ \\ Escuela Ciencias del Deporte \\ Universidd Nacional \\ Heredia, Costa Rica \\ mrmc2479@hotmail.com
}

Recibido 01-04-2010 • Aceptado 26-09-2010 • Corregido 05-10-2010

El juego es como una vela que ilumina el comportamiento del ser humano: es el resultado de la búsqueda de las mejores cosas que se hallan escondidas en lo más íntimo del ser

(Paredes, 2003, p. 121)

Resumen: El propósito de esta investigación fue analizar los factores que influirian en el estado estructural y administrativo de los campos de juegos en cuatro distritos urbanos del Cantón Central de la provincia de Heredia. En esta investigación mixta se analizó una muestra del $40 \%$ de los cien campos de juego en estudio, por medio de una hoja de evaluación del estado estructural de los aparatos, una entrevista estructurada y la técnica de recopilación pictórica. El estado general de los campos de juego se ve afectado por aspectos como desechos, la falta de basureros, la iluminación, entre otros. Asimismo, la diversidad de aparatos en los campos de juegos es escasa y el daño más frecuente es la herrumbre. El mantenimiento lo brindaba en la mayoría de los casos

\section{Introducción}

El juego es una acción instintiva en el ser humano. No necesita aprendizaje, surge de manera espontánea, y se basa en las necesidades de la edad de la persona. Esta actividad lúdica, según Paredes (2003) y García (2001), es placentera, espontánea, voluntaria y tiene un fin en sí misma. Se caracteriza por ser creativa, improvisada, incierta y gratuita; crea incertidumbre y ficción. 
la propia comunidad o la Municipalidad de Heredia y los planes de mantenimiento eran escasos o nulos. Los campos de juego son actualmente espacios poco seguros que cuentan con peligros como la corrosión de las estructuras, puntas filosas y aparatos dañados. Por lo tanto, requieren una atención inmediata de las autoridades pertinentes $y$, en su mayoría, no están cumpliendo con el objetivo de su creación.

Palabras clave: Campos de juego, recreación, estado estructural y administración.

\begin{abstract}
The purpose of this investigation is to analyze the factors that influence the structural and administrative statuses of playgrounds in four urban districts of Central County in the province of Heredia. In this mixed, predominantly quantitative investigation, a sample of $40 \%$ of the one hundred playgrounds under study was analyzed by using three instruments: a form for structural condition assessment, a structured interview and pictorial collection. The playground general state is affected by aspects such as waste, lack of trashcans and lighting among others. In these playgrounds, the diversity of equipment is scarce and the most common damage found was rust. Maintenance was provided in most cases by the community itself or the Municipality of Heredia, and maintenance plans were scarce or nonexistent. The playgrounds are currently unsafe spaces that have hazards such as structured corrosion, sharp edges and damaged equipment. The existing playgrounds require immediate attention from relevant authorities and the majority of these structures do not meet the goal of their creation.
\end{abstract}

Key words: Playgrounds, recreation, structural and administrative status.
Durante el juego, el cuerpo y el alma se involucran y dejan ver la realidad, los sueños, la imaginación, la conciencia, la crudeza, la sensibilidad, el pensamiento y los sentimientos de cada persona; así como su autenticidad y la personalidad que la caracterizan. Las poblaciones infantil, adolescente, joven, adulta y adulta mayor necesitan el juego a fin de cimentar las bases para una mejor vida y conservar o bien recuperar su comportamiento natural, su equilibrio vital (Paredes, 2003).

Para cada edad existe un tipo de juego adecuado a las necesidades emocionales, espirituales o físicas, según corresponda, mediante el cual se brinda la posibilidad de una transformación, al tiempo que el individuo se divierte y se sumerge en un mundo libre (García, 2001). El juego es una actividad que beneficia, de forma integral, el aprendizaje de conductas por medio del desarrollo de destrezas y conceptos específicos; así como el intercambio y la difusión de emociones y vivencias (Stillwell, 1987).

La contribución que otorga el juego a la exploración y al descubrimiento sirve de nexo con la naturaleza. En él se encuentran un sinfín de beneficios: facilita el proceso de socialización en las personas, potencia el desarrollo infantil, fomenta la curiosidad, estimula el sentido del humor y ayuda a regular las tensiones del individuo. De esta manera, posibilita la estructuración del lenguaje y del pensamiento, ejerce una función relajante y permite una evasión saludable de la realidad cotidiana. Mediante el juego se aprende a diferenciar entre el mundo de las fantasías y la realidad y posibilita el aprendizaje significativo de la población infantil (Paredes, 2003).

El juego es parte esencial en la vida infantil; ocupa casi todo el tiempo del infante, desde el momento en que se levanta hasta que se duerme (Stillwell, 1987). Gallahue y Vannier (1978, p. 42) mencionan: "si usted quiere saber cómo es un niño o niña, obsérvelos cómo juegan. Si usted está interesado en lo que ellos y ellas van a convertirse en un futuro, guíe su juego". 
Para la población infantil, el acto de jugar implica tres aspectos básicos: realizar actividades divertidas, estar en lugares divertidos y ser protagonistas del juego; pues el juego es su vida y el motor de su existencia (Wadell, 2001). Sin embargo, este instinto de jugar no es un comportamiento exclusivo de la edad infantil, aun cuando se crea que al llegar a ser personas adultas este instinto desfallece, no se debe dejar de jugar. Mediante el juego, las personas adultas pueden descargar las energías sobrantes, liberar las tensiones acumuladas, analizar sobre quiénes son, de dónde vienen y hacia adónde van, vivir el sentimiento del "yo puedo", tomar conciencia de sí mismas, así como establecer comunicación y relación con otros. En la persona adulta, el juego es de suma importancia para lograr un equilibrio psíquico (Paredes, 2003).

Es por esta importancia del juego en el ser humano que existen algunas legislaciones internacionales y nacionales que lo amparan. Un ejemplo de ellas se encuentra la Declaración Universal de los Derechos Humanos, adoptada y proclamada el 10 de diciembre por la Asamblea General de las Naciones Unidas (1948), en la cual se especifica en el Artículo 24: "toda persona tiene derecho al disfrute del tiempo libre". Las reglas de las Naciones Unidas para la Protección de los Menores Privados de Libertad son concretas en su principio general; por ejemplo, en su Artículo 47, esta normativa dispone que las personas menores de edad deben contar diariamente con el tiempo suficiente para realizar actividades de esparcimiento, practicar ejercicios físicos al aire libre o jugar. Además, si el clima lo permite, se debe proporcionar educación recreativa y física. Para realizar estas actividades, se debe contar con terrenos e instalaciones apropiadas y el equipo necesarios (Pavía, Lorente, Quinteros y Verbic, 2002).

En Costa Rica, también se especifican los derechos de las poblaciones de infantes, adolescentes y personas jóvenes, en cuanto a cultura, recreación y deporte. La Constitución Política de la República de Costa Rica, en el Capítulo VII, hace referencia al derecho de toda persona a la educación y a la cultura (Costa Rica. Tribunal Supremo de Elecciones, 1949). La Ley de la Niñez y la Adolescencia, Número 7739, en los Artículos 73 y 75, se refiere al derecho de las personas menores de edad a jugar y participar en actividades recreativas, deportivas y culturales, que permitan ocupar provechosamente su tiempo libre y contribuyan a su desarrollo integral. Dichos artículos citan al Ministerio de Cultura, Juventud y Deporte y las corporaciones municipales como entes responsables de proponer las políticas necesarias y ejecutar las acciones pertinentes para facilitar, a las personas menores de edad, los espacios comunales y nacionales adecuados. La infraestructura deportiva y recreativa estatal debe estar a disposición de diferentes grupos, en condiciones de plena igualdad para la práctica del deporte o actividades recreativas, de acuerdo con las reglamentaciones que se emitan (Fondo Internacional de Emergencia de las Naciones Unidas para la Infancia [UNICEF] y Defensoría de los Habitantes, 1998).

A su vez, la Ley General de la Persona Joven, Número 8261, establece como derechos de esta población, en el Artículo 4, incisos e) y k), el derecho a la recreación por medio de actividades que promuevan el uso creativo del tiempo libre, para que disfrute una vida sana y feliz. Además, tiene el derecho a convivir en un ambiente sano y participar en acciones que contribuyan a mejorar su calidad de vida (Fondo de Poblaciones de las Naciones Unidas y el Consejo de la Persona Joven, 2002).

La recreación es un derecho que, por ley, tiene toda persona. Pero, ¿por qué es tan importante? Esta importancia radica en la cantidad de beneficios que proporciona a las personas de todas las edades, sin importar etnias, credos, zonas, comunidades, grupos sociales, grupos minoritarios o ambientes. Por ejemplo, a nivel personal, se puede 
mencionar que la recreación previene problemas de salud, disminuye los hábitos sedentarios, la fatiga, la ansiedad, el estrés, el consumo de tabaco, alcohol, la hipertensión, el riesgo de enfermedades coronarias y problemas somáticos. Con todo esto, mejora la calidad de vida, el estado sociopsicológico, la autoestima, la autonomía, el humor, el bienestar personal, las relaciones interpersonales, la memoria, la capacidad de introspección y las funciones de los sistemas: cardiovascular, respiratorio, endocrino, entre otros. Las actividades recreativas son un medio para fomentar la amistad, la cooperación, el análisis y la resolución de conflictos, el aprendizaje de destrezas, habilidades y aptitudes, así como el aprecio y la valoración de la naturaleza, entre muchos otros beneficios (Salazar, 2002).

En la sociedad, las personas, por medio de la recreación, experimentan vivencias espirituales y fortalecen los lazos familiares y la amistad. Ella propicia el trabajo en equipo, mejora la cohesión familiar y grupal, la cooperación, el respeto por los demás, la toma de decisiones y la comunicación. Mediante las actividades recreativas se aprenden y fomentan los valores, tradiciones y costumbres de un pueblo, además del trabajo voluntario. Asimismo, ayuda a tomar conciencia de la importancia de las zonas protegidas, genera recursos para proteger el ambiente y los sitios históricos y culturales, promueve el crecimiento de la economía local y fomenta la educación y la recreación al aire libre. Se reducen los costos de los servicios médicos, de procedimientos y programas judiciales por comportamientos negativos, el vandalismos, los robos y las agresiones (Salazar, 2002).

Los espacios recreativos son un medio para estimular todos los beneficios anteriores y fomentar que las personas jueguen. Estos son una necesidad psicológica, un prerrequisito social y un atributo espiritual, ya que en ellos se expresan valores personales y sociales (Rico, 2002). Proveen además, un área neutral, segura y divertida, en donde la interacción consigo mismo y con otros se da en forma natural (Horning, 2005). Estos espacios recreativos se desarrollaron primero en lugares al aire libre como playas, parques, bosques, lagos o sitios con bellezas escénicas, que las personas visitaban con el fin de compartir, conocer o simplemente disfrutar sus vacaciones. Pero, con el pasar del tiempo, en las ciudades más urbanizadas surgió la necesidad de espacios para recrearse, donde se ofreciera una mayor supervisión del juego, con lo que nacieron los centros de recreación, polideportivos y los campos de juego (Kraus y Curtis, 2000).

Los campos de juego son áreas diseñadas, equipadas, localizadas y exclusivas para el juego. Estas incluyen equipo de juego, espacios protegidos, cercas, señalizaciones, rutas internas y diversas formas de vegetación y estructuras. Y son una parte fundamental de cualquier infante en su desarrollo físico, intelectual, social y emocional (Wadell, 2001). Es por ello que Hudson y Thompson (2001) establecen veinticuatro razones por las cuales se debe proveer de campos de juego a la población infantil.

A continuación se resumen las ocho razones más importantes, en orden descendente de prioridad: (a) un espacio para que las personas se recreen y el lugar necesario para que la población infantil pueda disfrutar el juego; (b) la seguridad en el ambiente que puede proporcionar un campo de juego, en especial, en las áreas urbanas; (c) la posibilidad de jugar libremente; (d) la interacción que se logra entre las personas que utilizan estos espacios; (e) el ejercicio que se realiza durante la estancia en este lugar; (f) la diversidad de actividades que brinda el campo de juego desde el punto de vista de oportunidad de movimiento; (g) la diversión y el ambiente social y físico que proporcionan, ya que la población infantil puede hablar, gritar y desenvolverse con naturalidad y (h) la posibilidad de jugar con otras personas.

Estos espacios ofrecen a la población usuaria una serie de beneficios. Por ejemplo, 
los campos de juego son un lugar de encuentro y comunicación. Un ámbito para desarrollar y practicar destrezas sociales, para experimentar la aceptación y el rechazo, para desarrollar amistades y para aprender acerca de la cooperación. Además, refuerzan el desarrollo físico. Las personas profesionales en parques y recreación visualizan los campos de juego como un área para que la población infantil desarrolle sus destrezas, habilidades y cualidades como correr, saltar, deslizarse, escalar, saltar, entre otras; es decir, ayuda en el desarrollo físico de acuerdo con la edad de las personas. A su vez, estos espacios fomentan la diversión. La población infantil no percibe el ambiente de la misma manera que las personas adultas lo hacen. Si se quiere beneficiar a la población infantil por medio de estos espacios lúdicos, las personas adultas deben colocarse en el mismo nivel o punto de vista que esta población. $\mathrm{O}$ sea, si se van a desarrollar áreas de juego, es necesario prestar mayor atención no solo a las diferentes características de la población infantil, sino también a diseñar estos espacios lúdicos de acuerdo con las necesidades que presenten esos grupos etáreos, el concepto de diversión que tengan y las condiciones culturales que posean. $\mathrm{Al}$ mismo tiempo, estos lugares aportan un sentido de seguridad o confianza a la persona que intenta manejar una situación que cambia y aun así logra ser capaz de tener éxito en una acción.

Con el fin de propiciar cambios, se debe incrementar la complejidad de las tareas de las actividades que se pueden realizar en los campos de juego, pero no incrementar la probabilidad de riesgo. Finalmente, los campos de juego facilitan el uso de la creatividad y el juego interactivo. La imaginación y la creatividad son atributos internos del ser humano, no externos. Un campo de juego creativo es aquel que provee elementos para la creatividad, el juego expresivo, el juego dramático, el juego cooperativo y el desarrollo cognitivo (Hudson y Thompson, 2001; Peterson, 2002).

A lo largo de su historia, los campos de juegos se han convertido en una fuente de oportunidades no solo para el cumplimiento de los derechos anteriormente señalados, sino también para propiciar actividades gratas y constructivas que pueden favorecer a los diferentes grupos etáreos, especialmente entre los seis y los catorce años (Butler, 1966). En todos estos lugares se escucha la risa y se observa la innovación, se demuestra la capacidad de ejecutar las acciones propuestas, poner a prueba las condiciones motrices y el desarrollo de habilidades y destrezas motoras. No importa si se disfruta a solas o con compañía. Estos espacios han suministrado oportunidades en el desarrollo de las destrezas necesarias para moverse eficientemente y han ayudado a compartir y afianzar la visión de mundo de las personas que los utilizan (Booth, 1988).

Por ejemplo, en Estados Unidos históricamente los campos de juego se han considerado una infraestructura recreativa de tipo tradicional. Estos espacios fueron diseñados primeramente para que las poblaciones infantil y joven experimentaran vivencias placenteras y desarrollaran a su vez, por medio del material y la infraestructura brindada, el juego creativo y exploratorio y aprendieran cosas nuevas (Kraus y Curtis, 2000). Sin embargo, para algunas personas no especialistas en el área recreativa, los campos de juego fueron $\mathrm{y}$ siguen siendo solamente un espacio físico (Rico, 2002). Por esa razón, las miradas disociadoras de los entes que se encargan de planificar, siguen viendo el patio escolar de juegos como un problema propio del sistema educativo; las plazas, los campos de juego y los espacios verdes, como un problema autónomo de las personas diseñadoras urbanas; y la actividad recreativa diaria, como un problema del sistema de salud (Pavía et al., 2002).

Con la finalidad de aprovechar más estos espacios de recreación pública, Butler sugirió, desde 1966, que estos campos de juego se ubiquen inmediatos a un centro educativo debido a que facilita el acceso de los grupos escolares durante y después de las horas de clases y, en otros momentos, se 
asegura su máximo uso, como un espacio comunitario. Actualmente en Costa Rica, esta situación no es muy usual, ya que dichos espacios lúdicos se localizan, por lo general en las urbanizaciones o residenciales (Butler, 1966).

Sin embargo, a menudo sucede que los campos de juego se construyen en espacios poco seguros. Esto coloca en peligro a las personas que los utilizan. Según, un estudio realizado en Turquía, el 83,3\% de los campos de juego está junto a una calle y el $60 \%$ no cuenta con ninguna barrera para proteger a la población infantil o evitar que esta se salga a la calle. La división en los apartados por edades se encontró en un $12 \%$, un $62,5 \%$ de la población infantil se encontraba bajo supervisión y el 95,8\% del equipo no era seguro (Acic, Gulbayrak y Turaci, 2004).

La Comisión para la Seguridad de los Productos para el Consumidor (CPSC) de Estados Unidos (citada por Hudson, Thompson y Olsen, 2004) indica que la población infantil resulta herida en gran número en los campos públicos de juego por las caídas a la hora de escalar, columpiarse y al usar los toboganes. Otro estudio de accidentes en los campos de juego, realizado en el mismo país por Lillis y Jaffe (1997), señala que la atención más frecuente en los hospitales como resultado de accidentes en los campos de juego son las fracturas en las extremidades superiores y que dos tercios de las personas atendidas que tienen que ser hospitalizadas han sufrido un accidente al escalar aparatos en los campos de juego. La población infantil con edades entre los ocho y los doce años se accidenta más al caer cuando escala y la población infantil entre cuatro y siete años, al caer de los toboganes. La población infantil menor sufre la mayor cantidad de heridas en la cabeza en los campos de juego en comparación con la población infantil mayor (O'Brien, 1998). Otro estudio, realizado por Wadell (2001), reporta que los accidentes más preponderantes en los campos de juego son causados por componentes en mal estado, equipo inapropiado, protección inapropiada de superficies y escaso mantenimiento.

Sin embargo, a pesar de que los estudios anteriores establecen como la más frecuente a una serie de accidentes en los campos de juego, una investigación de Petrido, Sibert, Dedoukou, Skalkidis y Trichopoulos (2002) señala que cerca del $50 \%$ de estos percances pueden ser prevenidos por un cambio en la estructura y el equipo. Esta reducción significativa generalmente se basa en medidas simples como una supervisión más cercana e incentivar de las personas usuarias para que usen zapatos apropiados y el equipo de protección cuando sea necesario.

Actualmente en Costa Rica no existen investigaciones que indiquen el estado real en que se encuentran los campos de juego. Basta con observar las estructuras para determinar el estado en que se encuentran. Con base en esta premisa de la observación, se ha determinado que gran cantidad de estas áreas recreativas, no cuentan con el mantenimiento necesario: los aparatos están destruidos, corroídos o abandonados. La infraestructura y los implementos son de alto riesgo para las personas que los utilizan y no se sabe quién los administra. La seguridad de los campos de juego se ve afectada por el vandalismo, el abandono que sufren y por los desechos que se encuentran en ellos. Aun peor, existen aparatos con ninguna o pocas medidas de seguridad u obsoletos, los que ponen en alto riesgo la seguridad de las personas que los utilizan.

Además, hoy en día existen evidencias de una disminución considerable en el nivel de actividad física de las personas en todas las edades y un aumento en sus actividades sedentarias (Craig, Mindell y Hirani, 2009; Hinkley, Crawford, Salmon, Okely y Hesket, 2008; Miles, 2007). La tecnología, el bombardeo comercial y la inseguridad ciudadana han influido en este cambio. Por ejemplo, el tiempo que las abuelas, los abuelos, los padres y las madres cuando eran infantes dedicaban al juego al aire libre 
ahora se emplea en actividades dentro del hogar y las diferentes formas de tecnología que con el tiempo han ido surgiendo (televisión, radio, Internet, computadora, juegos electrónicos, entre otros). Lo preocupante no es solo la inactividad de las personas sino el incremento tan significativos que se presenta a nivel mundial en enfermedades como la obesidad, la hipertensión, la diabetes tipo 2, tipos de cánceres, enfermedades coronarias, osteoporosis, entre otras. Todas ellas prevenibles en personas que practican actividad física regularmente. Asimismo, Sallis, Prochaska y Taylor (2000) sugieren que llevar estilos de vida activos durante la infancia reduce el riesgo de problemas de salud en los años subsiguientes de vida.

Además, existe una asociación entre los niveles de actividad física en las personas y el acceso que se tenga a las facilidades recreativas o deportivas (Bird, 2007; Spinks, Macpherson, Bain y McClure, 2006; Willenberg et ál., 2009). Sin embargo, los espacios físicos destinados para la recreación en los barrios o en las comunidades no solo son escasos, sino también se encuentran cercados con mallas o con portones cerrados con candados que impiden el acceso de la población. Aunque las calles no fueron diseñadas con un propósito recreativo, en su momento, fueron un lugar de disfrute, diversión, convivencia y amistad; actualmente se han convertido en un peligro. En las zonas urbanas, más específicamente, la imposibilidad de divertirse en las calles se ha visto incrementada por los altos niveles de inseguridad que se están experimentando. El juego y la diversión de antes, en las calles, parece ahora un sueño y estas estructuras son ya solo un medio para trasladarse de un lugar a otro. Es por ello que los campos de juego se conviertan en un recurso importante no solo como forma de aprovechamiento, sino también como medio para promover el aprendizaje de contenidos pedagógicos, la integración social, los estilos saludables de vida y la calidad de vida de la población. Estos espacios propician a su vez oportunidades para el mejoramiento de las destrezas motoras y favorecen el enriquecimiento, la diversificación y la exploración de las conductas en el desarrollo de la personalidad. Muchas de las destrezas motoras (ejemplo saltar, correr, brincar, coordinación, entre otras) se que aprenden durante la infancia se vuelven importantes para la actividad física durante la adultez (van Sluijs, McMinn y Griffin, 2007).

Las personas que visitan los campos de juego se divierten, juegan, experimentan alegría, y también obtienen otros beneficios como la socialización, la creatividad, la sensibilización de todos los sentidos, la toma de decisiones y el sentido de seguridad. Asimismo, se desarrollan valores como la tolerancia, el respeto, la cooperación, la responsabilidad, entre otros. Además, estos campos pueden, de manera orientada, favorecer el desarrollo integral, no solo de la población infantil, sino también de adolescentes, padres y madres de familia, abuelos y abuelas, ya que, con ellos se pueden rescatar las costumbres y tradiciones de una cultura, se puede fomentar la integración familiar, incrementar el tiempo de compartir y, lo más importante, mejorar la calidad de vida de las personas. Estos espacios lúdicos son, a su vez, una alternativa de movimiento para prevenir y combatir la cantidad de enfermedades que en el siglo actual esta enfrentando la población infantil. Así como una herramienta pedagógica para que las personas participantes de manera lúdica puedan vivenciar y aprender más allá de la cotidianidad de un aula.

Ante la situación actual en los niveles de salud de nuestra población, la inseguridad ciudadana, el desconocimiento del estado actual de los campos de juego en Costa Rica y el grado de importancia que estos espacios lúdicos pueden llegar a alcanzar en el desarrollo integral de las personas, y no saber si se llenan las necesidades de cada población y se ofrecen las condiciones óptimas de mantenimiento ${ }^{2}$, seguridad $^{3}$ e infraestructura ${ }^{4}$, es que surgió la necesidad de contar con un estudio 
que documentara el estado estructural ${ }^{5}$ y administrativo ${ }^{6}$ de los campos de juego. Con este estudio se logró identificar el estado real de estos espacios, estableciendo así una base científica que contribuyera en el proceso de planeamiento, mejoramiento ${ }^{7} \mathrm{y}$ aprovechamiento $^{8}$ de los campos de juego y proporcionar, a su vez, lugares seguros donde las comunidades puedan disfrutar el juego, la recreación y el tiempo libre. De igual manera, el estudio propició el cumplimiento de los derechos inalienables de la población costarricense.

Esta investigación tuvo como objetivos: (a) identificar los aparatos y el equipo que integran la infraestructura de los campos de juego en estudio; (b) valorar el estado de los aparatos y equipos que integran la infraestructura de los campos de juego en estudio; (c) evaluar el mantenimiento recibido por los campos de juego de parte del grupo responsable y (d) determinar las condiciones de seguridad en los campos de juegos en estudio.

\section{Metodología}

\section{Tipo de Investigación}

La investigación realizada en este trabajo fue de dos tipos. Por un lado, una investigación exploratoria y, por el otro, una investigación mixta dominantemente cuantitativa. Según Hernández, Fernández y Baptista (2003), una investigación exploratoria es toda aquella en la cual el objetivo fundamental es examinar un tema poco estudiado. En este caso, el tema de estudio acerca del estado estructural y administrativo de los campos de juegos en el cantón Central de Heredia y en el resto del país ha sido poco abordado, contrario a lo sucedido en otros países, como Estados Unidos, en donde sí se han realizado investigaciones, pero las condiciones socioeconómicas, la legislación y la mentalidad de la población son muy diferentes. Debido a esto, los hallazgos de este $\mathrm{u}$ otro país no se ajustan a las necesidades y características de la población costarricense. Por tal razón, mediante este estudio, se pretendió identificar variables promisorias que sirvan para establecer prioridades para investigaciones futuras en materia de espacios recreativos en Costa Rica.

Con respecto a la investigación mixta, este estudio se enfocó en un modelo dominante cuantitativo; sin embargo, posee un componente cualitativo que da soporte los resultados encontrados. La parte cuantitativa de este estudio corresponde al análisis descriptivo de la información recolectada con los dos instrumentos elaborados para tal fin. La parte cualitativa pretende enriquecer y fortalecer los datos descriptivos. Esta parte corresponde al análisis de contenido de las respuestas de la entrevista y de la recopilación pictórica (Hernández et ál., 2003).

\section{Sitios y Sujetos de Estudio y su Selección}

En este estudio se incluyó campos de juego y personas encargadas de estos sitios.

\section{Sitios de estudio}

En esta investigación se estudiaron los campos de juego de los cuatro distritos urbanos del cantón Central de Heredia: Ulloa, San Francisco, Mercedes y Central. Estos distritos cuentan con un total de 100 campos de juegos con plano catastrado, desglosados por distritos de la siguiente manera: Mercedes, 20; San Francisco, 55 y Ulloa, 25. Para el estudio se tomó una muestra probabilística (Hernández et ál., 2003) del $40 \%$ de los campos de juego que cumplían con los requisitos establecidos en el estudio. Por lo tanto, esta investigación incluyó un total de 40 campos de juegos distribuidos por distritos de la siguiente manera: 8 en Mercedes, 22 en San Francisco y 10 en Ulloa. Ningún campo de juego del cuarto distrito, el Central, se incluyó en 
esta investigación porque no cumplían con los criterios de selección preestablecidos.

\section{Selección de los Sitios de Estudio}

Antes de iniciar el proceso de selección de los campos de juego, el estudio se delimitó a cuatro distritos (Ulloa, San Francisco, Mercedes y Central) debido a que cuentan con características de distritos urbanos. El quinto distrito, Vara Blanca, está catalogado como distrito rural, criterio que no fue contemplado para este estudio. Los cuatro distritos que se escogieron para la investigación fueron seleccionados de acuerdo con las características de distrito urbano, señaladas en la Ley de Planificación Urbana Número 4240 (Costa Rica. Asamblea Legislativa, Leyes vigentes por nombre de la ley, 1978)

Una vez seleccionados los distritos, se procedióa elaborar unlistadodecaracterísticas para escoger la muestra de los campos de juegos del cantón Central de Heredia. Este listado se le entregó al Director Operativo de la Municipalidad de Heredia para que de los 400 campos de juegos existentes en el cantón, se seleccionaran aquellos que cumplieran con los siguientes criterios:

- Poseer plano catastrado.

- Estar inscritos como terrenos municipales.

- Estar a cargo de la Municipalidad o las asociaciones de desarrollo.

- Estar ubicados en lugares residenciales o comunales.

- Tener un mínimo de 75 lotes o 200 personas que vivieran alrededor.

Posteriormente, de los 100 campos de juego que cumplieron los criterios antes mencionados, se procedió a realizar una selección estratificada en forma aleatoria por tómbola (Hernández y et ál. 2003) del 40\% de la muestra por distrito. Gómez (1990) sugiere que en una muestra representativa cuanto mayor sea la homogeneidad de la población, menor es la muestra que se requiere para obtener conclusiones de un cierto grado de confianza. Sin embargo, Hernández et ál. (2003) señalan que cuanto mayor sea el tamaño de la muestra, mayor confianza se tendrá que es representativa de la población. Asimismo, Gómez (1990) recomienda que al aumentar el tamaño de la muestra, se reduce el error probabilístico. Por consiguiente, el $40 \%$ utilizado como muestra en este estudio, pretende aumentar la representatividad de la población y disminuir el error probabilístico.

Una vez seleccionada la muestra de los sitios de estudio, se procedió a solicitar una carta de aprobación por parte de la Municipalidad para que la investigadora pudiera realizar las visitas pertinentes a los campos de juegos seleccionados, sin ningún contratiempo con las comunidades.

\section{Sujetos de Estudio}

Los sujetos del estudio fueron los encargados legales del mantenimiento por parte de la Municipalidad y un representante de la asociación, junta o grupo de vecinos que se encargaba de brindar el mantenimiento real a estos espacios lúdicos. A todas estas personas se les realizó la entrevista estructurada.

\section{Instrumentos}

Los instrumentos que se utilizaron para la recolección de la información fueron:

1. Hoja de medición deloscampos dejuego, subdividida en tres grandes temas: mantenimiento, infraestructura y normas de seguridad. La hoja contuvo una escala de valoración de "muy bueno" (5 pts.), "bueno", "regular", "malo" y "muy malo" (1pto.). Además, contó con un total de 21 preguntas cerradas. Este instrumento se utilizó para medir los objetivos específicos uno, dos, tres y cuatro. 
2. Entrevista estructurada acerca del mantenimiento: se le aplicó al encargado legal por parte de la Municipalidad y las asociaciones, juntas o grupos de vecinos que se encargaban de brindar el mantenimiento real a cada campo de juego. La entrevista contempló 11 preguntas cerradas acerca del financiamiento y los aspectos de mantenimiento del lugar. Este instrumento se utilizó para medir el objetivo específico tres.

3. Cámara digital Sony CYBER SHOT 5.0 MEGA PIXELES semiprofesional: con esta cámara se tomaron 20 fotos por campo de juego. Este material se subdividió en diez fotografías para identificar el estado de la infraestructura, cinco para las normas de seguridad y cinco para el mantenimiento. Este instrumento se utilizó para medir los objetivos específicos uno, dos, tres y cuatro.

La hoja de medición y la entrevista fueron elaborados tomando como base de la experiencia de la investigadora, un instrumento de inspección de un parque de juego (Salazar, 2006a), una lista de chequeo para la supervisión de parques de juego (Salazar Salas, 2006b) y un instrumento de medición de las instalaciones recreativas de la Universidad de Carolina del Norte (Cavnar et ál., 2003). Estos dos instrumentos fueron validados por juicio de personas expertas: tres personas profesionales en el área de Recreación y dos en el área de Arquitectura.

\section{Procedimientos para Recolectar la Información}

Una vez obtenida la validez de los instrumentos elaborados, se procedió a visitar uno a uno los campos de juego seleccionados para el estudio. Al llegar a cada campo de juego, primero se aplicó la hoja de medición; en segunda instancia se realizó la recopilación pictórica y, finalmente, se buscó a las personas de la comunidad encargadas del mantenimiento del campo de juego para realizar la entrevista correspondiente. Paralelamente al proceso de visitas de los campos de juego, se entrevistó tanto a las personas encargadas de brindarles el mantenimiento (Jefe de Aseo, Vías y Sitios Públicos y Jefe del Departamento de Obras) como a los funcionarios a cargo en la Municipalidad de Heredia.

\section{Análisis de la Información Recolectada}

Una vez realizadas las observaciones, conducidas las entrevistas y tomadas las fotografías, se procedió a tabular los datos, realizar el análisis estadístico respectivo y clasificar las fotografías. Para el análisis cuantitativo de la hoja de medición y la entrevista estructurada de los campos de juego, se utilizó el programa Microsoft Office Excel 2003, con el cual se trabajó las bases de datos y se efectuó el análisis estadístico descriptivo (frecuencias absolutas y porcentajes totales e individuales). Para el análisis cualitativo de la técnica de recopilación pictórica, se utilizaron los programas ACDSee 7.0 y Adobe PhotoShop CS, con el fin de mejorar la calidad y el tamaño de las fotos. Además, con el programa Microsoft Office Word 2003 se agruparon las fotografías con base en los criterios de juicio del instrumento de observación.

\section{Resultados y discusión}

Producto de las visitas, los resultados obtenidos y los objetivos establecidos para este estudio, se determinó que 32 de los terrenos destinados para la construcción de los campos de juego en el cantón Central de Heredia se estaban empleando según lo establecela ley Número 4220 dePlanificación Urbana. Estos campos de juego contenían áreas diseñadas, equipadas, localizadas 
y exclusivas para el juego, que incluían aparatos, espacios protegidos, cercas, señalizaciones, rutas internas y diversas formas de vegetación y estructuras (Wadell, 2001). A su vez, una de estas áreas lúdicas que se encontraba invadida por precaristas. Sin embargo, los siete lotes restantes eran municipales y se encontraban baldíos, llenos de desechos, escombros y charcos. A pesar de ser terrenos destinados para campos de juego, no contaban con ninguna estructura ni diseños y corrían el riesgo de ser invadidos para ser utilizados con otros fines, como vivienda. Es importante que las comunidades tomen conciencia de que estos espacios han sido otorgados por ley y que, según el Reglamento para el Control Nacional de Fraccionamientos y Urbanizaciones, Artículo 3, Inciso 6.2.7, en caso de que estos espacios no se dejen acondicionados, la constructora debe cancelar un monto establecido por la Municipalidad para que, posteriormente, ella lo habilite (Costa Rica. Instituto Nacional de Vivienda y Urbanismo [INVU], 1982). Por consiguiente, en el resto de este capítulo el número máximo de campos de juego que se reportará será de 39.

A pesar de que el estado general de los terrenos donde se localizaban los campos de juego era "bueno", en un 62\% existe un $4 \%$ de estas áreas que estaban localizadas en un terreno "malo" o "muy malo". Estos lugares no solo ponían en peligro a la población que los utilizaba sino que incumplían con las disposiciones que la ley establece en el Artículo 3, Inciso 6.2. del Reglamento para el Control Nacional de Fraccionamientos y Urbanizaciones. Dicha normativa indica que los terrenos destinados para áreas públicas deben tener una topografía de calidad mayor o igual al promedio de terrenos (Costa Rica. INVU, 1982). A su vez, Hudson, Mack y Thompson (2000) enfatizan que un uso eficaz de todo el terreno se da cuando se facilita la supervisión y la operación, mediante la cuidadosa disposición de los aparatos o juegos y la adecuada ubicación de caminos y senderos en relación con los principales rasgos geográficos y la seguridad de la población. Según Ewert y Plumb (1999), las superficies deben ser accesibles para personas en sillas de ruedas, con andaderas y algunas otras discapacidades móviles.

En este estudio también se encontró que 31 de los terrenos destinados para campos de juego no eran accesibles para las personas con discapacidad. Hay que considerar que Hudson et ál., (2000), Blumenau, Rovira-Beleta y Cuyás (1996) y la Ley 7600 de Igualdad de Oportunidades (Lépiz y Jiménez, 2000) eran claros en establecer que estos espacios de juego, al igual que otras edificaciones, debían facilitar el acceso de cualquier persona a estas áreas sin discriminar a aquellas con discapacidad. Sin que esto signifique que se deban hacer modificaciones extremas a las estructuras, es necesario ajustar la infraestructura para que todas las personas puedan disfrutar de igual manera de estos espacios lúdicos. Blumenau y otros (1996), por su parte, amplían que las hamacas no deben estar instaladas cerca o sobre un camino y no se deben colocar estructuras de escaleras o aceras cerca de un tobogán. Debe también contar con rampas con barrotes anchos y profundos o pasamanos que permitan ir a las torres y estructuras para escalar, igualmente con hamacas más bajas para que las personas en sillas de ruedas o con alguna otra discapacidad puedan acercarse a tales aparatos con facilidad. Estas estructuras se deben equipar con manillas y barandillas suplementarias. Todas estas disposiciones de accesibilidad fueron escasamente encontradas en los campos de juego en estudio, por lo que es necesario reestructurar estos espacios y velar por el cumplimiento de las leyes, para que así todas las personas sin excepción puedan gozar de los beneficios de los campos de juego.

El primer objetivo específico del estudio fue identificar los aparatos y el equipo que integraban la infraestructura de los campos de juego en estudio. Los resultados se detallan a continuación. De los 
$32(80 \%)$ de los campos de juego que poseían estructuras, los cuatro aparatos más encontrados fueron hamacas, toboganes y pasamanos, en 28 campos de juego, y los sube y bajas en 22 de ellos. Dentro de las áreas destinadas para descansar o supervisar, el rancho se presentó en 21 de los campos de juego, seguido de las bancas en 14 de ellos.
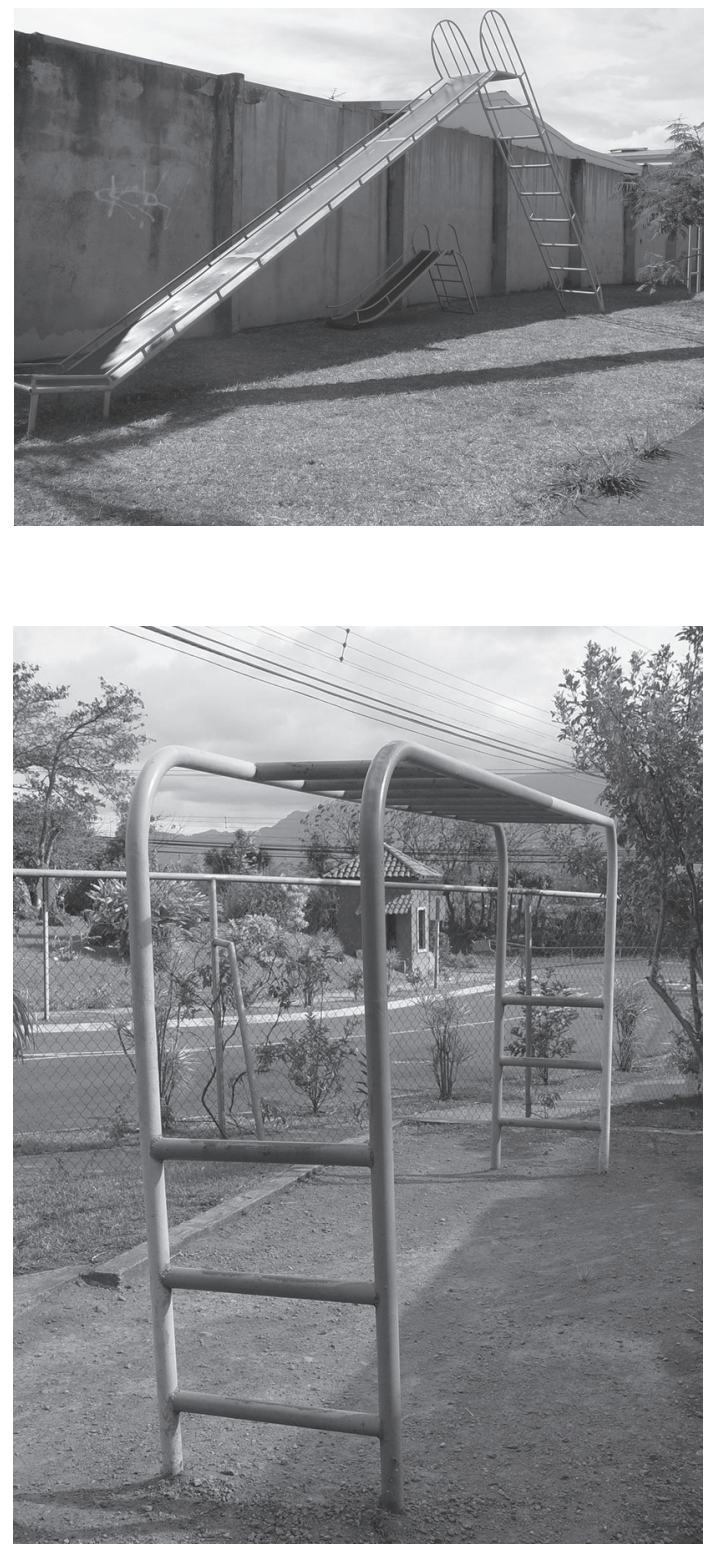

Asimismo, se encontraron otros elementos como: fosas de arena en 10 campos de juego, mesas para merendar en ocho, superficie de juego en siete y con una frecuencia menor los cubos de cemento, rayuela, llantas, redes para escalar, barras, túneles y argollas. Algunos de los aparatos más frecuentes se muestran en la ilustración 1.
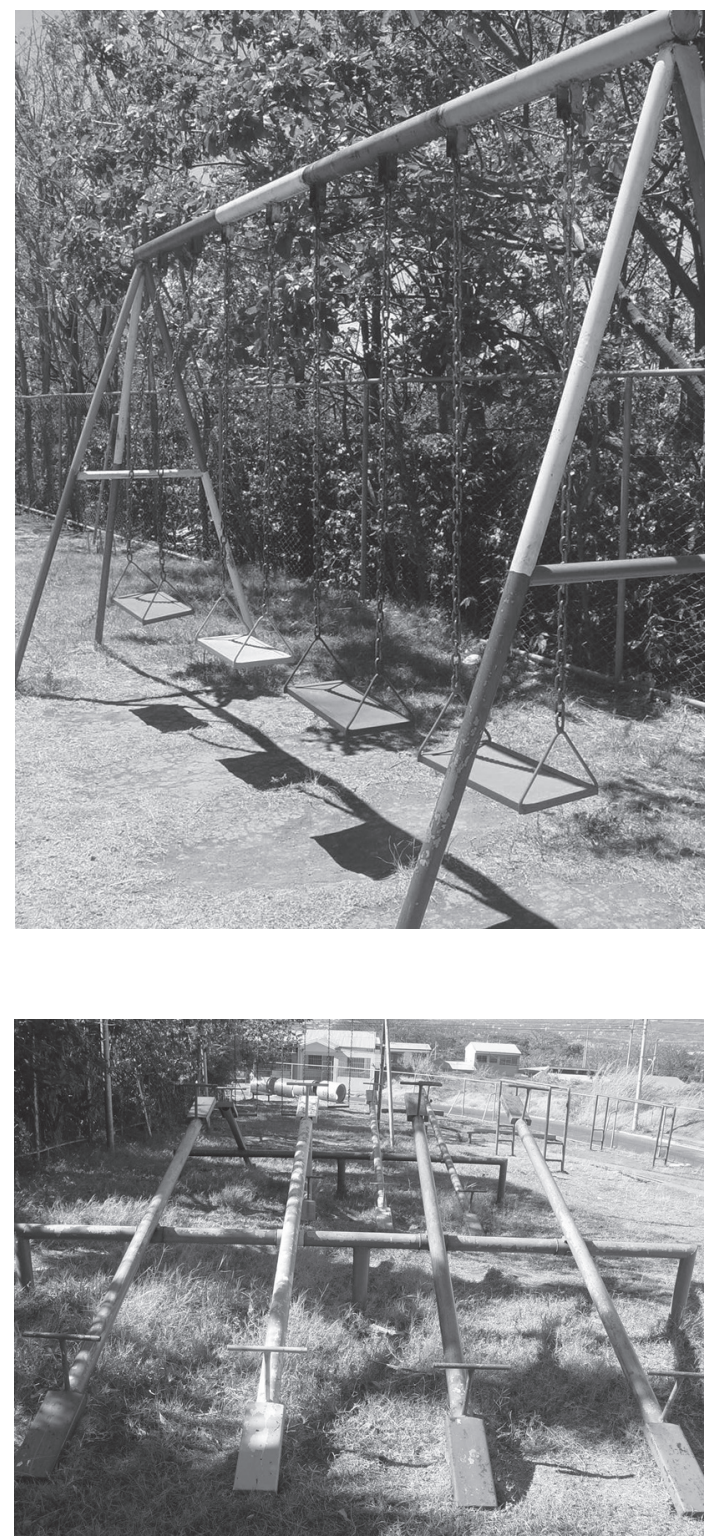

Ilustración 1. Las cuatro infraestructuras más encontradas en los campos de juego. 
Los campos de juego también incluían otros componentes en la infraestructura; por ejemplo, las fuentes de agua para la hidratación de las personas visitantes. Un $85 \%$ (33) de los 39 terrenos asignados para campos de juego no contaban con estos, únicamente el 15\% (6) sí las tenían. De esos seis campos de juego que sí poseían fuentes, en tres estaban en "mal" estado; en dos, en condición "regular"; y en uno, en "buen" estado. Los desagües, por su parte, estaban ausentes en 38 (97\%) de los 39 terrenos destinados para los campos de juego analizados. Los basureros estaban presentes en únicamente el 26\% (10) de los campos de juegos. De los 10 campos de juegos con basureros, siete contenían basura y el estado de $70 \%$ del los basureros fue superior o igual a "bueno".
Otra infraestructura encontrada fue la iluminación, presente en el 46\% (18) y ausente en el 54\% (21). Asimismo, las aceras estaban presentes en el 54\% (21). El estado de las mismas en 14 de los campos de juego era superior o igual a "bueno" y en 7 se encontraban en estado inferior o igual a "regular". Solamente 20\% (8) de los campos de juegos eran accesibles, el $80 \%$ (31) no cumple este mandato de la Ley 7600 "Igualdad de oportunidades para las personas con discapacidad". El embellecimiento (flores, plantas, árboles, arbustos, piedrilla y paredes pintadas) dentro de los campos de juego estaba presente en $61 \%$ (24). Algunos ejemplos de los elementos mencionados anteriormente, se pueden observar en la ilustración 2.
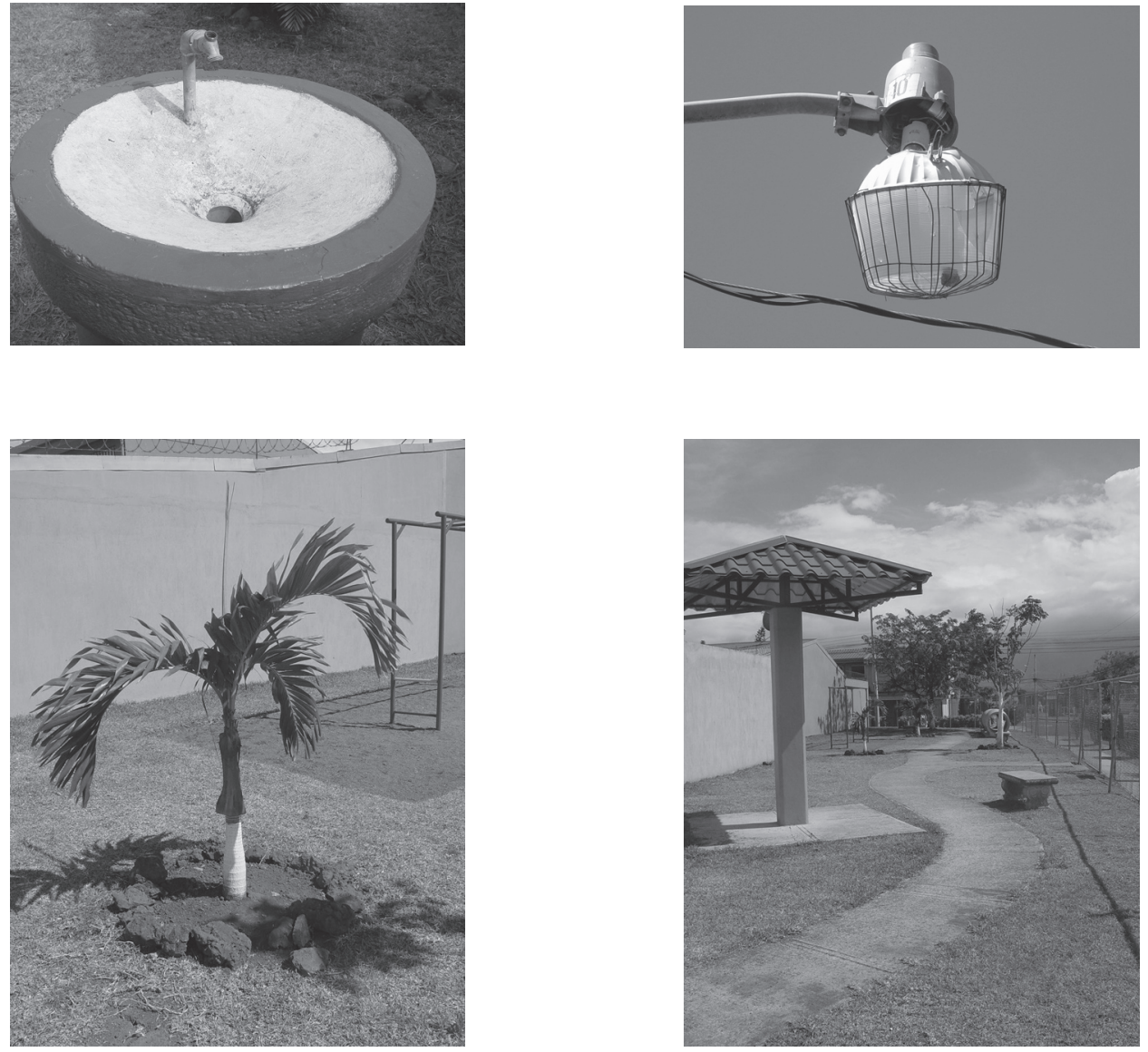

Ilustración 2. Algunos componentes de la infraestructura en los campos de juego. 
Con estos resultados se puede concluir que la diversidad de aparatos en los campos de juego era escasa y no atendía la observación de López y Estapé (2002), quienes recomiendan que, en caso de que la diversidad dentro de un campo de juego sea poca, se puede ampliar con estructuras en las cuales las formas irregulares, curvilíneas y alargadas prevalezcan en lugar de las estructuras cuadradas y lineales que fomentan la monotonía. Se podrían, también, incorporar montículos y desniveles que fomenten la fantasía y la imaginación. Esta posición es respaldada por Booth (1988), quien señala que el material suelto da interés y vida a un campo de juego y tiende a satisfacer las exigencias creativas e inventivas del propio mundo de juego infantil. Es esencial, también, crear una atmósfera de intimidad por medio de las cercas internas. Además, no solo se puede realizar juego a nivel del suelo, sino que también se puede montar una plataforma en lo alto de un árbol, juegos de escalar, juegos de construir una cueva subterránea o incluso brindar a la persona las herramientas 0 materiales necesarios para que incursione en el juego de aventura (López y Estapé, 2002). Se sugiere a las comunidades o a las personas encargadas de la administración tomar en cuenta estas recomendaciones, una vez que decidan mejorar los campos de juego.

El segundo objetivo específico del estudio consistía en valorar el estado de los aparatos y equipos que integraban la infraestructura de los campos de juego. Los resultados se detallan a continuación. De los 39 terrenos usados para campos de juego, el estado general en que se encontraban dos (5\%) de ellos es "muy bueno"; 10 (26\%), "bueno"; 12 (31\%), "regular"; ocho (20\%), "malo" y siete (18\%), "muy malo".

En cuanto al estado, el material y los daños que poseían cada una de las infraestructuras antes mencionadas, los resultados son los siguientes. En el caso de los aparatos, el metal fue el material más utilizado en 23 hamacas (82\%), 24 toboganes (86\%), 25 pasamanos (89\%), 19 sube y bajas (86\%), tres argollas (75\%) y dos barras para columpiarse (67\%). El cemento prevaleció en aparatos como: ocho fosas de arena (80\%), tres superficies de juego (42\%), la totalidad de los túneles, la rayuela y los cubos de cemento. En el caso de las redes para escalar, dos (67\%) estaban elaborados con madera y cuerda y las llantas en su totalidad estaban fabricadas con una combinación de materiales de hule natural y sintético.

La tabla 1 resume el estado de todos los aparatos encontrados en los 32 campos de juego.

En síntesis, el estado de los aparatos, de manera general se determinó que un 73\% se encontraban en estado igual o inferior a "regular", 26\% estaba "bueno" y solamente un $1 \%$ se encontraban en un estado "muy bueno". Otro factor medido fue el material del cual estaban constituidos los aparatos de los campos de juego. Los más frecuentes fueron el metal y el cemento. El metal prevaleció en aparatos como hamacas, toboganes, pasamanos, sube y bajas, argollas y barras para columpiar. El cemento por su parte fue más encontrado en aparatos como las fosas de arena, las superficies de juego, los túneles, la rayuela y los cubos. Las zonas de descanso o supervisión, por su parte, estaban elaboradas frecuentemente de cemento, como en el caso de las bancas y las mesas para merendar. En estructuras como el rancho, prevaleció el metal. Booth (1988), Hudson et ál, (2004) y Christiansen (2002) señalan algunos tipos de materiales que se han venido utilizando para el diseño de los campos de juego. Por ejemplo, para la elaboración de los aparatos del campo de juego, se pueden utilizar diferentes materiales, como ladrillo, piedra, plástico, concreto, metales con tratamiento anticorrosivo, acero, madera tratada, polímeros sintéticos o fajas vulcanizadas naturales, siempre y cuando se ajusten a la zona y a las condiciones climatológicas del lugar en donde se ubiquen los campos de juego. En la construcción de los campos de juego de este estudio, no se tomó en cuenta la recomendación establecida por Christiansen (2002), ya que los materiales utilizados se ajustaban al terreno pero no a las condiciones climáticas y, como consecuencia, 
los aparatos estaban sufriendo daños. En caso de no contar con recursos económicos suficientes para equipar los campos de juego se pueden utilizar materiales de desecho o menos costosos, siempre y cuando cumplan con las normativas adecuadas de seguridad y mantenimiento. En las ilustraciones 3, 4, 5 , se pueden observar ejemplos de aparatos según los criterios de juicio utilizados en la tabla 1.

Tabla 1

Resumen del estado general de los aparatos en los 32 campos de juego

\begin{tabular}{lrrrrrr}
\hline Aparato & Muy bueno & Bueno & Regular & \multicolumn{1}{c}{ Malo } & Muy Malo & Frecuencia \\
\hline Hamacas & $0(0 \%)$ & $3(11 \%)$ & $19(68 \%)$ & $5(18 \%)$ & $1(3 \%)$ & 28 \\
\hline Toboganes & $1(3 \%)$ & $6(21 \%)$ & $18(64 \%)$ & $3(11 \%)$ & $0(0 \%)$ & 28 \\
\hline Pasamanos & $0(0 \%)$ & $10(36 \%)$ & $15(53 \%)$ & $2(7 \%)$ & $1(3 \%)$ & 28 \\
\hline Sube y Bajas & $0(0 \%)$ & $2(9 \%)$ & $12(54 \%)$ & $6(27 \%)$ & $2(9 \%)$ & 22 \\
\hline Fosas de arena & $0(0 \%)$ & $1(10 \%)$ & $3(30 \%)$ & $4(40 \%)$ & $2(20 \%)$ & 10 \\
\hline Argollas & $0(0 \%)$ & $4(100 \%)$ & $0(0 \%)$ & $0(0 \%)$ & $0(0 \%)$ & 4 \\
\hline Túneles & $0(0 \%)$ & $2(50 \%)$ & $2(50 \%)$ & $0(0 \%)$ & $0(0 \%)$ & 4 \\
\hline Barras para columpiar & $0(0 \%)$ & $2(67 \%)$ & $0(0 \%)$ & $1(33 \%)$ & $0(0 \%)$ & 3 \\
\hline Red para escalar & $0(0 \%)$ & $3(100 \%)$ & $0(0 \%)$ & $0(0 \%)$ & $0(0 \%)$ & 3 \\
\hline Llantas & $0(0 \%)$ & $1(50 \%)$ & $0(0 \%)$ & $0(0 \%)$ & $1(50 \%)$ & 2 \\
\hline Rayuela & $0(0 \%)$ & $0(0 \%)$ & $1(100 \%)$ & $0(0 \%)$ & $0(0 \%)$ & 1 \\
\hline Cubos cemento & $0(0 \%)$ & $1(100 \%)$ & $0(0 \%)$ & $0(0 \%)$ & $0(0 \%)$ & 1 \\
\hline Total & $1 \%$ & $26 \%$ & $52 \%$ & $16 \%$ & $5 \%$ & 134 \\
\hline
\end{tabular}

$\mathrm{n}=32$
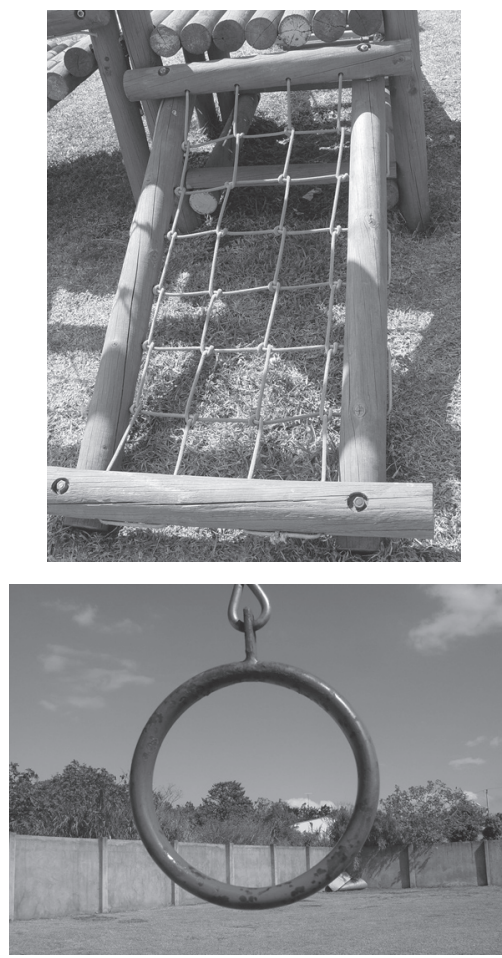
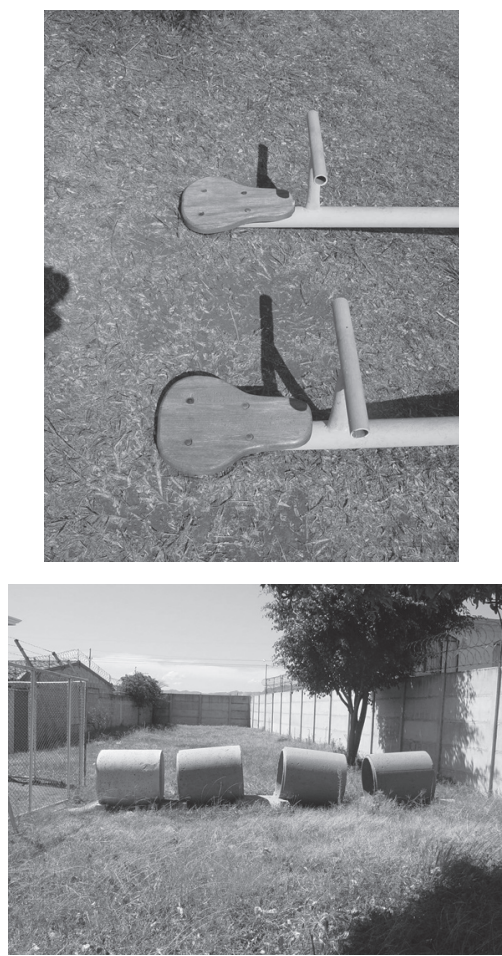

Ilustración 3. Aparatos en buen estado en los campos de juego. 

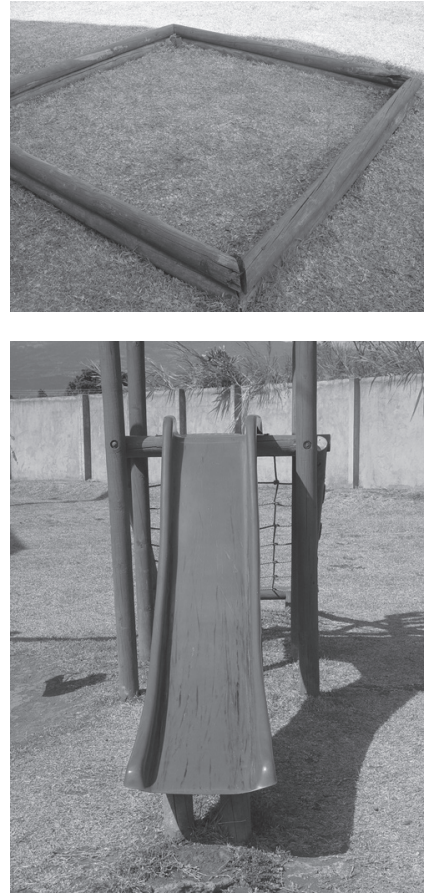

Ilustración 4. Aparatos en estado regular en los campos de juego

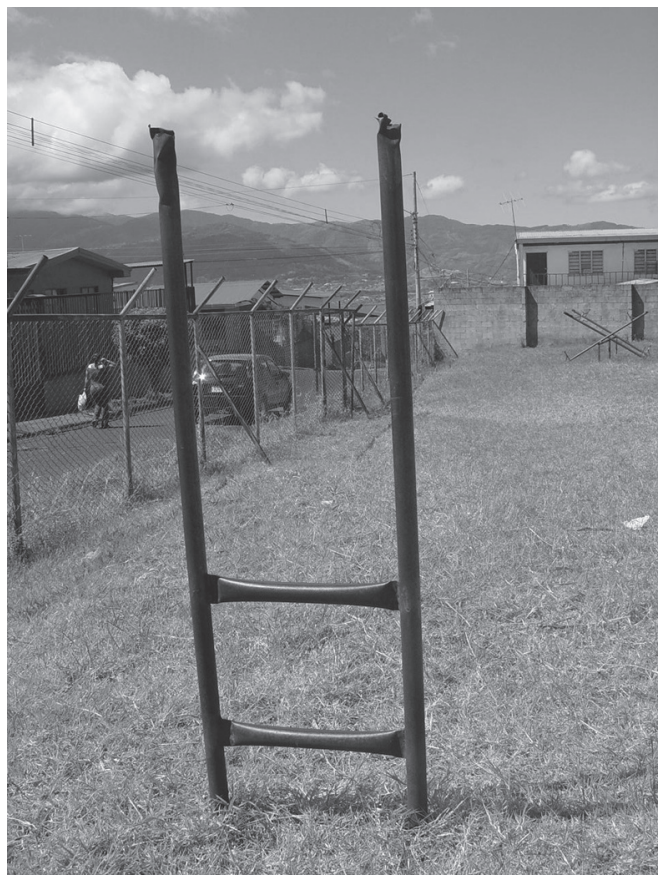

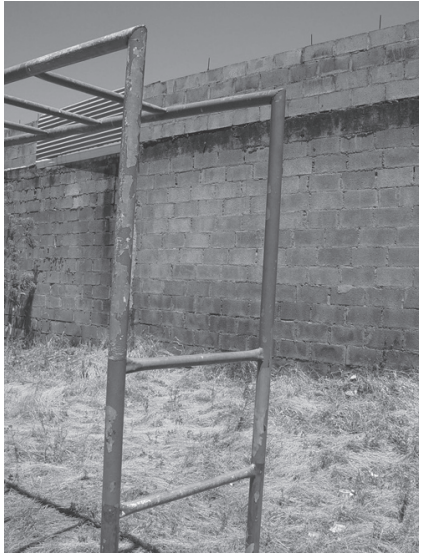
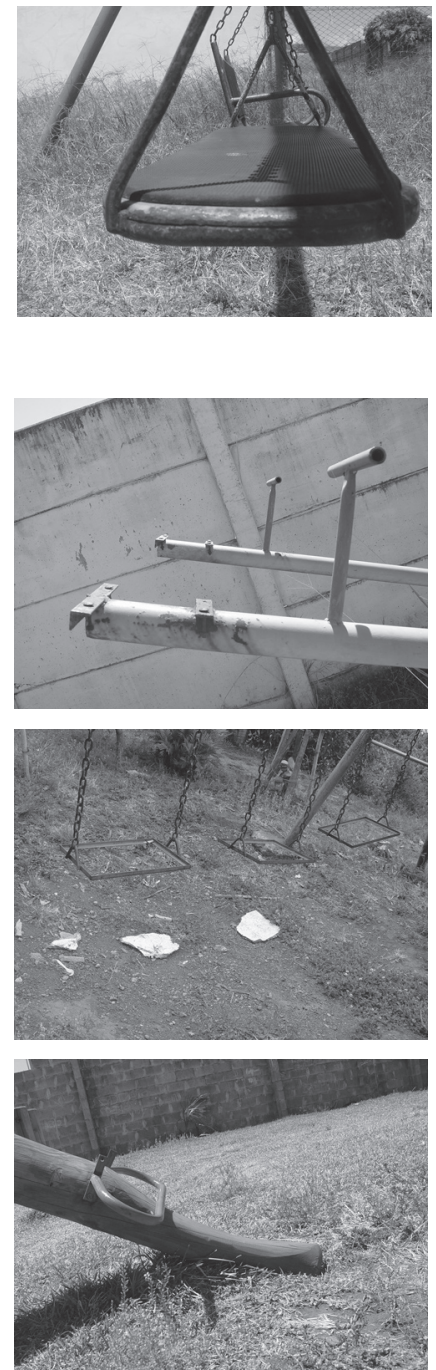

Ilustración 5. Aparatos en mal y muy mal estado en los campos de juego. 
Uno de los daños que se encontró con mayor frecuencia en los aparatos de toda la infraestructura fue la herrumbre. Por ejemplo, 22 de los campos de juego que tenían hamacas presentaban esta condición. Lo mismo ocurrió en 24 de los campos de juego con toboganes, en 21 de estos espacios con pasamanos, en 19 con sube y bajas, en dos con argollas, en dos con barras para columpiarse y en uno con redes para escalar. Asimismo, otro daño que se
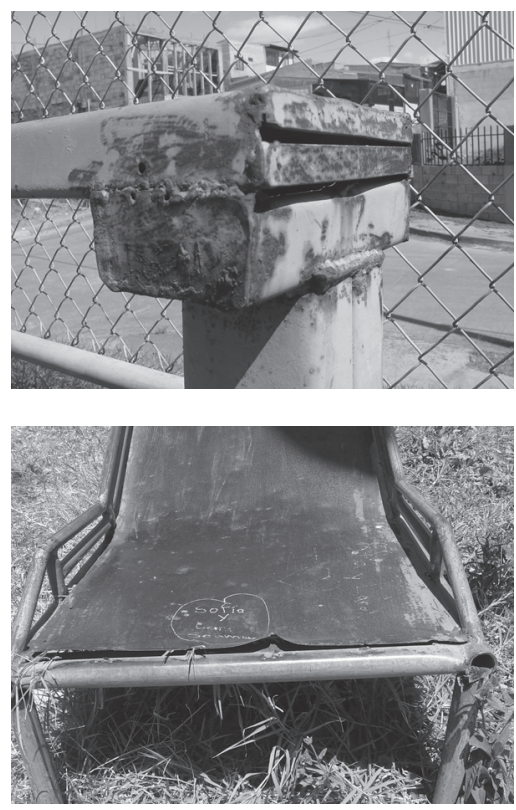

presentó frecuentemente en las estructuras fue el estar despintadas. Esta situación se evidenció en 15 de los campos con hamacas, en 20 con toboganes, en 20 con pasamanos, en 15 con sube y bajas, en dos con argollas, en dos con túneles, en uno con barras para columpiarse, en uno con redes para escalar y en la totalidad de las llantas, la rayuela y los cubos de cemento. Algunos ejemplos de los daños señalados anteriormente, se pueden observar en la ilustración 6 .
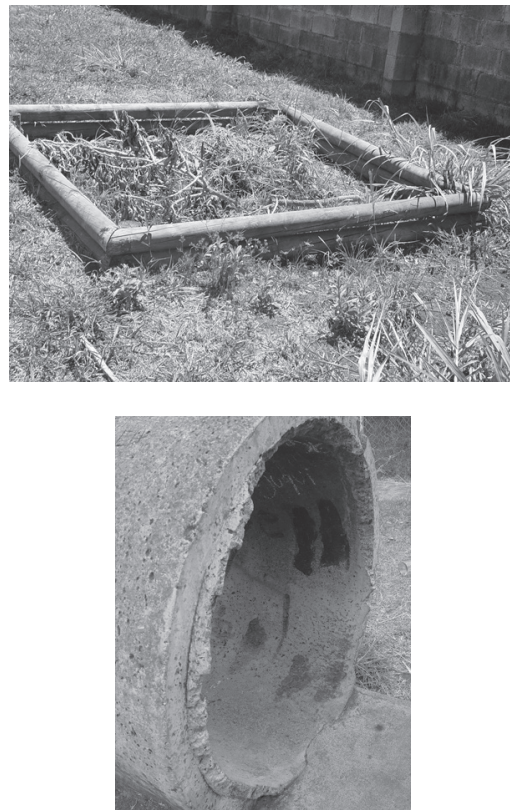

Ilustración 6. Algunos de los daños presentados con mayor frecuencia en los campos de juego.

Otros daños encontrados en los aparatos fueron: estructuras quebradas en todos los túneles y con cubos de cemento; daños estructurales en tres fosas de arena y en tres superficies de juego; metal levantado en los toboganes de 5 campos de juego; ocho fosas de arena abandonadas; 10 campos de juego con hamacas remendadas; dos de estos espacios lúdicos con escombros y la falta de agarraderas en los sube y bajas de seis campos de juegos, entre otros.

El material más encontrado en la infraestructura para descansar o supervisar a la población infantil fue el cemento. Este se observó en cinco campos de juego con mesas para merendar y 10 con bancas.
En el caso de los ranchos, el metal fue el material más frecuente en $13(62 \%)$ de los mismos. El estado de estos elementos fue "regular" en el 86\% de los ranchos, el $57 \%$ de las bancas y el $88 \%$ de las mesas para merendar. La herrumbre fue el daño más frecuente en ocho de los campos de juego con ranchos y en dos con mesas para merendar. Otros daños encontrados son bancas quebradas en siete de ellos; grafitis en tres; el techo de los ranchos dañados en cinco y estructura despintada en seis campos de juego con ranchos. Cabe mencionar, además, que se encontró mucha suciedad en las mesas para merendar (excremento de pájaros). 
Las fotografías de la ilustración 7 presentan los dos materiales predominantes en las estructuras de los campos de juego.
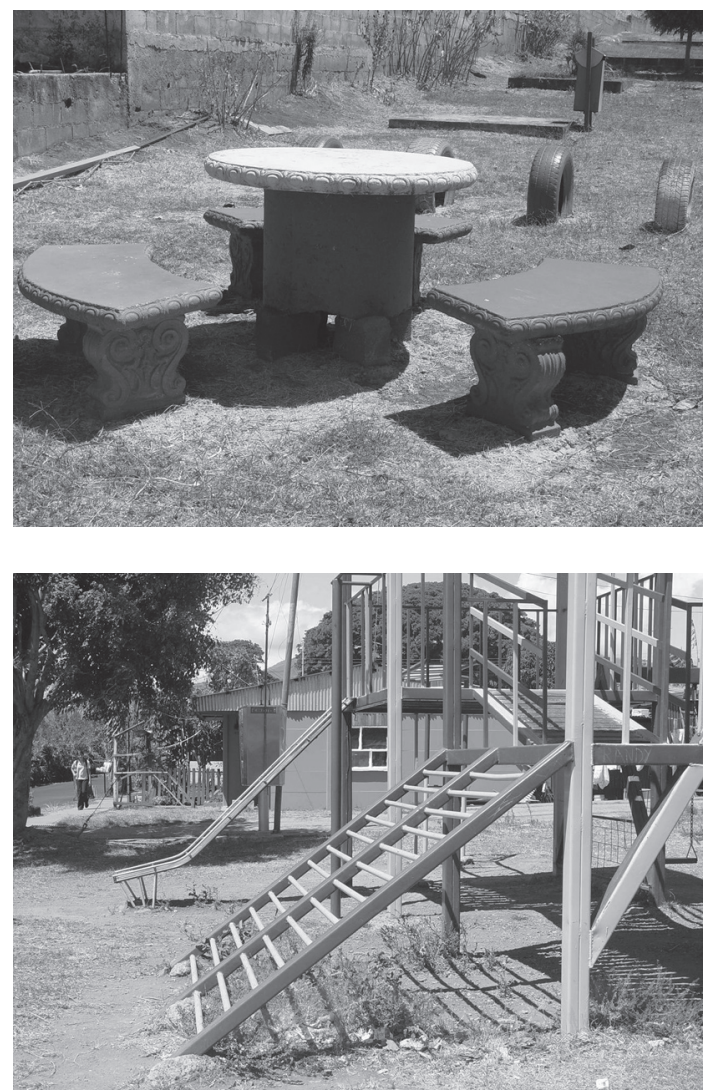

Ilustración 7. El material más encontrado en la infraestructura de los campos de juego.

Estos resultados evidencian la situación real en las que se encuentran estos campos de juego, la cual se aleja del ideal propuesto por las personas expertas, ya que un aspecto importante dentro de la administración de los terrenos o campos de juego es el mantenimiento de los recursos materiales que hay en ellos.

El tercer objetivo específico del estudio fue evaluar el mantenimiento recibido por los campos de juego de parte del grupo responsable. Los resultados fueron los siguientes. Todos los campos de juego en estudio son terrenos propiedad de la Municipalidad de Heredia. Lamentablemente como lo mencionan
Galera y Llusá (1996), el mantenimiento es uno de los aspectos que menos se toma en cuenta y se aplica únicamente en casos extremos, cuando los aparatos u objetos están deteriorados. Esta carencia se puede verificar en los campos de juego que legalmente son de la Municipalidad de Heredia. El mantenimiento que esta entidad les brinda a estos espacios se basa únicamente en la corta de árboles y césped, la poda de árboles y la soldadura de aparatos dañados. En este estudio, los aspectos de mantenimiento anteriores no se realizaban por medio de un plan permanente, sino conforme las denuncias, llamadas o solicitudes de las comunidades. Además, el personal designado para estas funciones era escaso: un chapeador y un soldador, con un chapeador de refuerzo en la época de invierno para todo el cantón Central de Heredia. Solo en la época lluviosa estos servicios municipales contaban con un peón de refuerzo.

A raíz de los datos proporcionados por los encargados municipales acerca del mantenimiento de los campos de juego y las entrevistas estructuradas a las personas en las diferentes urbanizaciones que realmente les brindaban el mantenimiento, se encontró que 20 (51\%) de los 39 terrenos asignados para campos de juego eran atendidos por la Municipalidad y 25 (64\%) de los 39 eran atendidos permanentemente por las juntas, asociaciones o grupos de vecinos. Es importante señalar que 14 de los 39 terrenos destinados para campos de juegos no cuentan con mantenimiento comunal, ya que no poseen ni un grupo de personas, asociación o junta de vecinos que se encarguen de ellos. Por lo tanto, se están convirtiendo en espacios abandonados y se incrementa el riesgo de vandalismo y la posibilidad de que sean utilizados para otros fines como el consumo de drogas, alcohol, relaciones sexuales, vivienda, entre otros. Galera y Llusá (1996) consideran que si no se cumple el objetivo fundamental del mantenimiento de los campos de juego, el cual es mejorar su estructura, su aspecto estético, prevenir 
accidentes o lesiones, garantizar su higiene y aumentar su duración, estos seguirán siendo espacios poco atractivos e inseguros para las personas que los emplean. Esto también se aplica a los campos de juego en Costa Rica.

Según Christiansen (2002), aún los mejores campos de juego deben ser revisados regularmente y recibir mantenimiento. De las 25 entidades comunales entrevistadas, dos indicaron que no les daban mantenimiento a los campos de juego y 23 reportaron que sus campos de juego sí lo recibían; pero de estos 23 solo en uno de los campos de juego el mantenimiento lo brindaba la Municipalidad, en dos las constructoras y en 20 lo realizaban las comunidades. Según las manifestaciones de los grupos, juntas o asociaciones de vecinos, el mantenimiento que se les proporcionaba consistía en la corta de césped, pintar los aparatos y, esporádicamente, en brindarles mantenimiento. Esto indica que el concepto de mantenimiento utilizado por los grupos, juntas o asociaciones de vecinos no es el establecido por la literatura, sino que es un mantenimiento correctivo, no preventivo.

Asimismo, de las recomendaciones dadas por Hudson et ál. (2000) sobre aspectos que se deben incorporar en un plan de mantenimiento se señalan: cortar el césped, podar los arbustos, limpiar las piletas y estructuras, así como cuidar cada detalle propio de un espacio de este tipo. En este estudio se estableció que 15 de las personas entrevistadas respondieron que no se contaba con un plan de mantenimiento, y únicamente ocho de ellas afirmaron tenerlo. En la totalidad de estos ocho planes de mantenimiento se involucraban acciones como: abrir y cerrar portones, recolección de basura, reparación de aparatos y pintura. Además, en siete de ellos se contempla la búsqueda de fondos y, en cinco, la supervisión. La acción menos frecuente es la señalización en solo uno de ellos. Las personas encargadas de controlar que este plan se cumpla son los grupos y juntas de vecinos o las asociaciones en un 100\%.

Según Kutska (2001), Galera y Llusá (1996) y Ewert y Plumb (1999), existen tres categorías de mantenimiento que se deben incluir en el plan para lograr calificar y cuantificar las tareas. La primera es el mantenimiento rutinario, la segunda es el mantenimiento preventivo y la tercera categoría abarca la renovación y/o el reemplazo de los aparatos u otros de la infraestructura. Christiansen (2002) señala la importancia de que a algunas estructuras como puntos de lubricación, superficies aisladas, superficies de soporte y soportes de la estructura se les deben dar un mantenimiento específico. En caso de haber protuberancias en superficies duras, estas pueden provocar laceraciones, pinchazos o estrangulaciones, y la basura, como vasos quebrados, piezas o pedazos de plástico y desechos de otra índole, produce que el lugar luzca descuidado y sucio. Parker (2000) recuerda la importancia de considerar también, en el mantenimiento, las estructuras que pueden verse afectadas por infestación de insectos, condiciones ambientales, áreas húmedas o salinas, acidez del aceite, la corrosión o la herrumbre, el vandalismo, los grafiti y el hurto de materiales.

A su vez, siete de los 23 campos de juego recibían mantenimiento una vez al mes y seis cada 3 meses o cuando hubiera fondos. El costo mensual aproximado del mantenimiento para nueve de los 23 campos de juego oscilaba entre $\$ 16.000$ (dieciséis mil colones) y $\$ 30.000$; en seis de estas áreas, el costo de mantenimiento oscilaba de $\phi 15.000$ o menos y, en cuatro, el precio era de entre $\$ 61.000$ o más. De esos 23 espacios lúdicos, en 21 de los casos la misma comunidad era la encargada de brindar los fondos; en uno de los casos la Municipalidad, por medio de partidas específicas, y en otro, la constructora. De ahí se puede determinar que la atención brindada a estas estructuras es mínima al tomar como base las recomendaciones 
de mantenimiento mencionada por autores como Galera y Llusá (1996), Ewert y Plumb, (1999), Parker (2000), Kutska (2001) y Christiansen (2002), con respecto al mantenimiento de las estructuras, las zonas de vigilancia, los cuidados que se deben tener para contar con un espacio limpio, seguro, agradable, cómodo y que brinde las condiciones necesarias para que las personas usuarias se recreen.

Con respecto al horario de uso de los 25 campos de juego cuyas personas encargadas fueron entrevistadas, el 14 (56\%) contaban con un horario de uso. De esos 14 espacios lúdicos que poseían horario, en seis casos era de 7:00 a.m. a 6:00 p.m.; en cuatro, de 6:00 a.m. a 8:00 p.m.; dos de ellos, de 6:00 a.m. a 10:00 p.m. y dos casos más contaban con horarios propios acorde con la persona encargada dentro de la comunidad para esta función. Asimismo, se determinó que de los 32 campos de juego, un $84 \%$ de ellos tenían más de 4 años de existencia, factor que debían tomarse en cuenta a la hora de realizar el plan de mantenimiento correspondiente, debido a que puede ser un indicador importante para tomar decisiones, ya sea de reemplazo o reparación de los aparatos.

El estado general del terreno de los 39 destinados para campos de juego era "bueno" en un 62\% de los casos, "regular" en un 26\%, "muy bueno" en un 8\%, "malo" en un 2\% y "muy malo" en 2\%. Razón de ello fue que en 28 de los terrenos se encontraron diferentes tipos de desecho, entre ellos, y en gran proporción, basura, escombros, grafitis y en menor cantidad vidrios, ramas cortadas, botellas, plásticos, neumáticos, charcos, piedras y excremento de perro. Fue preocupante encontrar que únicamente 11 de los terrenos estaban libres de desecho. El factor de la basura podría verse incrementado aún más porque 29 de los terrenos asignados para campos de juego no contaban con basureros y los 10 que sí poseían se encontraban llenos de desechos o con basura no retirada en largo tiempo. Estas cifras son evidencia de que la infraestructura de estos espacios no se encontraban en condiciones óptimas y requerían una atención inmediata, ya que de no ser así se ponían en riesgo la integridad de las personas que los visitaban. Algunos de los desechos más frecuentes se muestran en la ilustración 8.
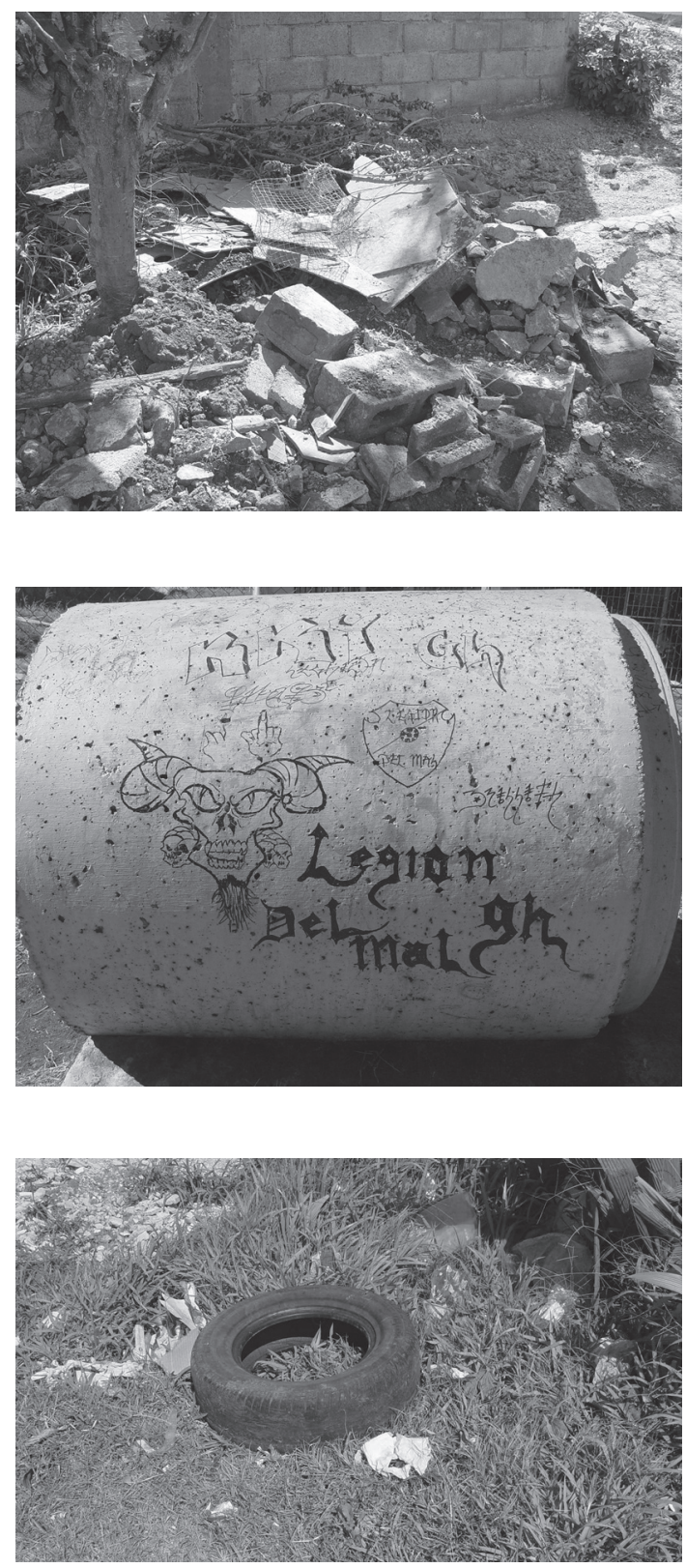

Ilustración 8. Algunos tipos de desechos encontrados en los campos de juego. 
Asimismo, la altura del césped en 19 de los terrenos era media. También, 33 de los terrenos asignados para campos de juego no poseían fuentes de agua para la hidratación y de los 6 campos de juego que sí las tenían, la mitad estaba en "mal" estado. Además, la mayoría de los campos de juego no contaban con desagües y 21 de ellos no se encontraban iluminados. Sin embargo, 24 de estos espacios tenían algún elemento que los embellecía. Los aspectos de embellecimiento más frecuentes fueron árboles en 20 terrenos, seguidos por arbustos en 16 de estas áreas. Otros de estos aspectos presentados con muchísima menos frecuencia fueron las piedrillas decorativas, flores, plantas, paredes pintadas, entre otras decoraciones. Además, 21 de los terrenos contaban con aceras, de las cuales un $62 \%$ estaba en "buen" estado y solo un $33 \%$ se encontraban en "regular" y "mal" estado. Los elementos que prevalecían en las zonas para descansar o supervisar eran el rancho y las bancas. Por ejemplo, Hudson et ál. (2000) señalan que se debe brindar comodidades para las personas que usan los campos de juego, como son las fuentes de agua potable, los desagües, la iluminación, el embellecimiento, los lugares para sentarse y los espacios de estacionamiento. Estos son elementos que se deben considerar indispensables en un campo de juego.

Además, estos autores y Butler (1966) mencionan que todos los elementos de la infraestructura como las bancas, los ranchos, los aspectos de embellecimiento, las fuentes de hidratación, la iluminación, los basureros, la higiene del lugar, entre otros, se han vuelto vitales no solo a la hora de planificar y organizar, sino que también los proporcionan armonía, embellecimiento, comodidad, atracción, accesibilidad y seguridad a las personas que visitan los campos de juego para recrearse. La mayoría de los datos encontrados en el estudio se contraponen a lo indicado en la literatura, ya que los campos de juego no cuentan con los elementos necesarios para que dichos lugares sean seguros, cómodos y cumplan con los requerimientos de las diferentes poblaciones que los utilizan.

En síntesis, el tipo de mantenimiento que se les brindaba a los campos de juego del cantón Central de Heredia podría afectar las estructuras por los altos porcentajes de corrosión y deterioro que sufrían. Además, la poca información con que contaban las comunidades acerca de cómo, cuándo y qué tipo de mantenimiento se les debe dar muestran un desconocimiento por parte de ellas, a pesar de que existían pruebas pictóricas en las que se puede observar claramente el estado estructural de dichos espacios lúdicos.

Determinar las condiciones de seguridad de los campos de juegos en estudio era el cuarto objetivo del estudio. En relación con dicho objetivo se presentaron los siguientes resultados. De los 39 terrenos asignados para campos de juego, en este estudio se identificó que 18 de estos espacios no se encontraban cerca de peligros como calles principales, ríos, pendientes, declives, entre otros. Sin embargo, el $61 \%$ de los campos de juegos presentaron terreno con declives o pendientes. Por otra parte, 36 de estos espacios lúdicos se encontraban abiertos, de modo que eran de fácil acceso para la población, aunque existían tres de ellos cerrados a la población. Además, 25 estaban cerrados totalmente con malla, cuatro con malla parcial y $10 \mathrm{de}$ ellos no tienen ningún tipo de malla de protección. Ewert y Plumb (1999) sugieren que los campos de juego de barrios estén cerrados, recomendación que no se cumple en todos los campos de juego de este estudio. Este cierre es una medida de seguridad que pretende impedir que las personas infantes se alejen del lugar, facilitar la supervisión o vigilancia y evitar la incursión proveniente del exterior (López y Estapé, 2002). Otro aspecto importante por considerar es que se debe tener cuidado con la ubicación de entradas y salidas del campo de juego. En caso de que los portones permanezcan cerrados, se debe contar con un plan de evacuación. 
Ewert y Plumb (1999) señalan que la seguridad cumple un papel importante en los campos de juego. Es esencial que las personas participantes, las personas visitantes o espectadoras, así como las cuales laboran en dichos campos de juego se sientan seguras cuando se encuentren en estos espacios lúdicos. Sin embargo, la totalidad de los 39 terrenos asignados para campos de juego analizados no exhibían el reglamento de uso y 38 de ellos no poseían señalamientos o letreros que orientaran a las personas visitantes; solamente uno contaba con dos letreros. Hudson et ál. (2004) apoyan la idea de educar a la población visitante por medio de señales y letreros que despierten la conciencia sobre la relevancia de la supervisión o de otras conductas que se deben respetar, rescatar o sancionar en los campos de juego, ya que los accidentes en estos lugares ocurren cuando las personas utilizan equipo que no es apropiado para la edad o cuando no cuentan con supervisión (Hudson, Mack y Thompson, 2002). Este aspecto de señalamiento y letreros se debe considerar como una de las primeras acciones de mejoramiento que debe realizarse en los campos de juego, pues si no se orienta a las personas sobre cómo utilizar los aparatos y cómo comportase en los campos de juego, no se podrá exigir que los cuiden, los valoren y les den el uso que requieren.

Antes de ejecutar un programa de seguridad es importante tomar en cuenta los peligros que pueden estar asociados a los campos de juego. De los 32 espacios en cuestión que contaban con algún tipo de aparatos, estos presentaban los siguientes peligros: $63 \%$ contaban con una estructura corroída, $41 \%$ contenían aparatos con puntas filosas y $37 \%$ mostraban aparatos rotos o dañados. En cuanto a los aparatos, $33 \%$ tenían una altura superior a la recomendada, el 13\% contaba con barandas anchas o estas eran inexistentes (13\%), el $4 \%$ se encontraba cerca de otra estructura y otros (10\%). Los peligros más frecuentes en ellos fueron la presencia de corrosión en el $93 \%$ de las hamacas, el 71\% de los toboganes, el $64 \%$ de los pasamanos, el $72 \%$ de los sube y bajas, el $75 \%$ de las argollas y el $67 \%$ de las barras para columpiarse. Igualmente, se vio con frecuencia la altura superior a la recomendada en un $79 \%$ en los toboganes, un $89 \%$ de los pasamanos y un $33 \%$ de las barras para columpiarse. Asimismo, el 50\% de las hamacas, el $100 \%$ de las rayuelas, el $64 \%$ de los sube y bajas, el 100\% de los túneles, el 100\% de los cubos de cemento y el $30 \%$ de las fosas de arena contaban con aparatos rotos o dañados; el 57\% de los toboganes poseían barandas anchas o no las tenían; el 79\% de los pasamanos, el 100\% de los túneles, el $100 \%$ de los cubos de cemento y el $79 \%$ de las fosas de arena tenían puntas filosas en su estructura.

Según los datos anteriores, los campos de juego en estudio poseían todos los peligros mencionados por autores como: Ewert y Plumb (1999); Hudson et ál (2000) y Frost, Sutterby, Therrell, Brown y Thornton (2002). Dichos peligros, según la literatura, son: las superficies por utilizar dentro del campo de juego; las estructuras que pueden dejar atrapadas a las personas que las utilizan; el tipo de material empleado en la construcción de los aparatos; todo aquel material que sobresalga, prolonga o proyecta; las esquinas, las puntas filosas y los bordes; las estructuras que pueden pinchar, aplastar y trasquilar; el material de la superficie de caída; la altura de los aparatos; el material utilizado de manera inapropiada para las diferentes alturas y la zona de uso del aparato. Por lo tanto, los peligros presentes en los campos de juego en estudio concordaban con la literatura encontrada y provocaban lugares inseguros, abandonados, descuidados y de un riesgo permanente para las personas que disfrutan de los beneficios de estos lugares, los cuales en condiciones óptimas podrían mejorar su calidad de vida. Algunos de los peligros más frecuentes se muestran en la ilustración 9. 

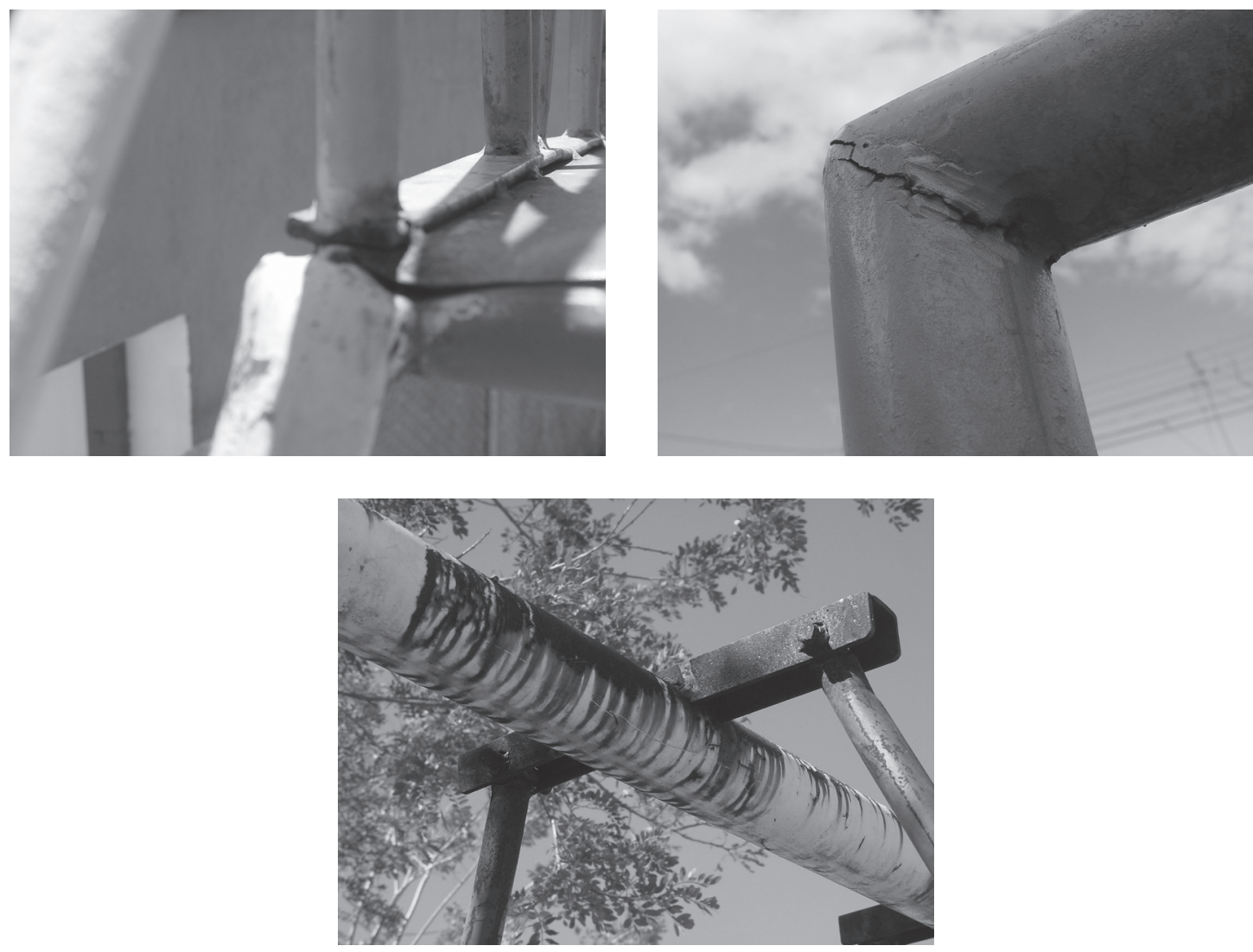

Ilustración 9. Algunos de los tipos de peligros encontrados en los campos de juego.

La superficie más encontrada al final de los aparatos fue el césped en un $32 \%$ de los casos, seguida por la tierra dura en un $22 \%$, la tierra dura combinada con césped en un $18 \%$, la piedrilla en un $11 \%$, la tierra combinada con piedrilla en un $10 \%$, la tierra movida en un $4 \%$ y el cemento en un 3\%. En el estudio se encontró que el $77 \%$ de las superficies al final de los aparatos estaban libres de objetos. Sin embargo, existía un $23 \%$ de superficies que presentaban objetos tales como vidrios, excrementos de perro, escombros, basura, entre otros. Algunos tipos de superficies utilizadas en los campos de juego se pueden ver en la ilustración 10.

A lo largo del tiempo, la superficie de estas estructuras ha sido de gran importancia. Por ejemplo, las superficies de arena blanda y las de hierba han resultado agradables para caminar y desarrollar el sentido del tacto. Las de concreto, a pesar de ser duras y lisas, han sido útiles para los juegos que implican bicicletas, carretillos para empujar y coches de juguete. Otro tipo más moderno, según Kilitzus, Meuli, Jank, Scheurer y Léchot (1996), es la superficie sintética. Esta ofrece muchas ventajas como: resistencia a la intemperie, estabilidad, flexibilidad, resistencia al envejecimiento y al desgaste; además, es antideslizante, pero el costo de construcción es muy elevado. Según Ewert y Plumb (1999), se recomienda la instalación de material sintético (caucho, poliuretano) o naturales. Ahora bien, debido a que los materiales sintéticos son bastante caros considerando las condiciones económicas del país, se podría tomar en cuenta la 
sugerencia de estos autores en cuanto a reemplazarlo con tierra o areneros en zonas determinadas. Si se mantienen las zonas de arena, esta debe ser removida y renovada periódicamente para que no se compacte y provoque accidentes.
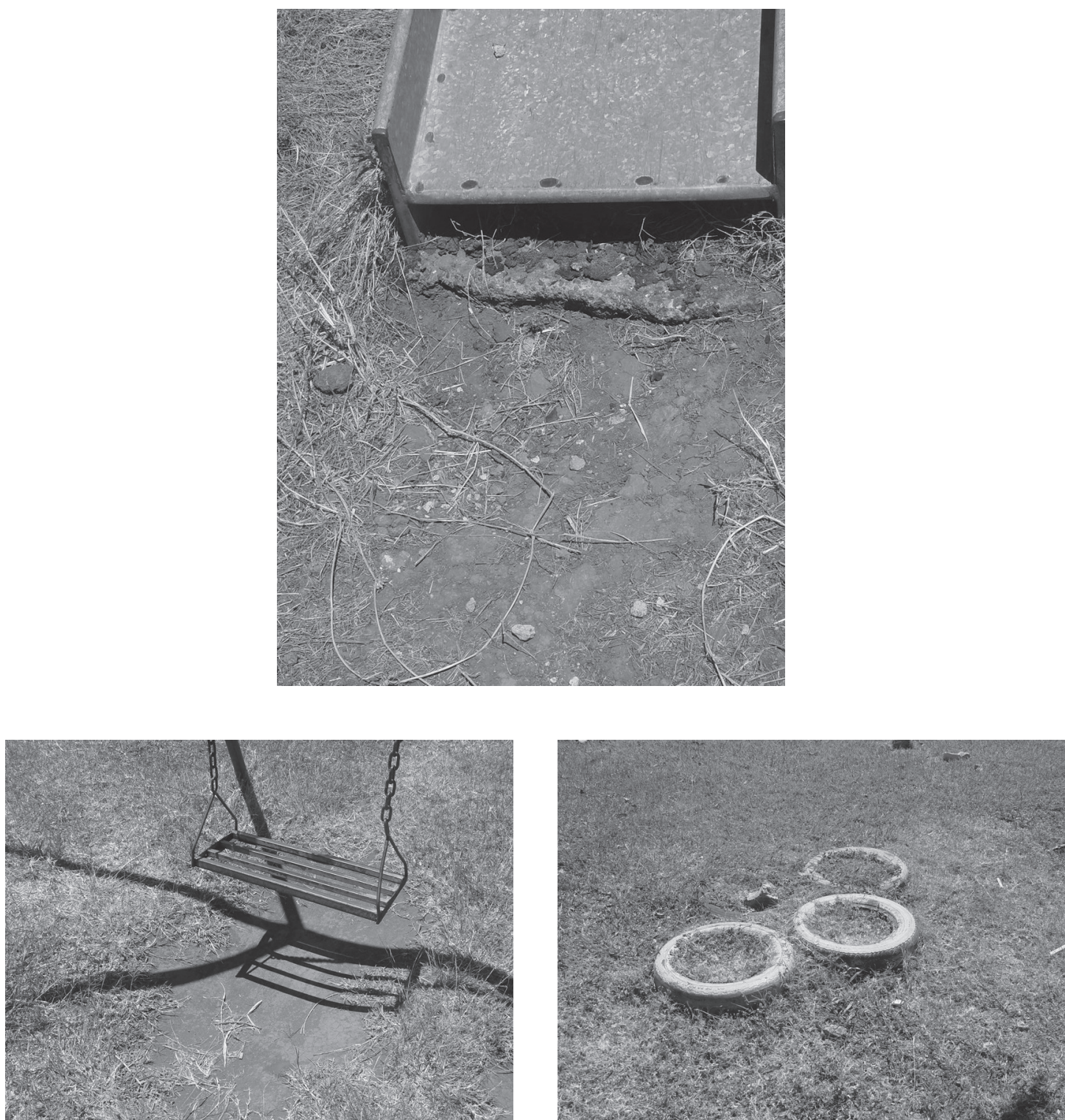

Ilustración 10. Algunos tipos de superficies utilizadas en los campos de juego.

Es importante que las personas encargadas de dar mantenimiento y que administran los campos de juego del cantón Central de Heredia, lo mismo que cualquier otro campo de juego, tomen en cuenta las recomendaciones dadas por autores como Hudson et ál. (2000), Frost et ál. (2002) y
Booth (1988), con respecto a las superficies seguras. Ellos sugieren que para contar con una superficie segura, se deben tomar en cuenta tres factores: la altura de los aparatos, el material utilizado de manera inapropiada para las diferentes alturas y la zona de uso del aparato. Por ejemplo, un 
terreno de arena y aserrín proporciona una almohadillada para aquellas actividades en las que se fomente el trepar. El césped es la mejor superficie para la población infantil. La superficie de cemento, de arcilla o material bituminoso o sintético son aptos para los campos que requieran un rebote preciso y que estén sometidos a un uso intensivo. Se han obtenido excelentes resultados con el uso del asfalto de corcho en el campo de juego infantil. El costo de este material es relativamente alto pero bajo en mantenimiento.

Considerando los datos, las superficies utilizadas en los campos de juego en estudio no eran las recomendadas en la literatura, además de que no se les estaba dando el mantenimiento necesario y producían superficies inseguras para la población del cantón Central de Heredia.

\section{Conclusiones}

En cuanto a la infraestructura se concluye que la diversidad de aparatos en los campos de juego era poca, lo que producía espacios monótonos y aburridos que no fomentaban la fantasía, la imaginación y la creatividad de la población usuaria. Los campos de juego carecían de las condiciones de accesibilidad establecidas en cumplimiento de la Ley Número 7600 de Igualdad de Oportunidades, limitando así el acceso a todas las poblaciones costarricenses.

El estado de los aparatos y equipos que integraban la infraestructura de los campos de juego estaba caracterizado por terrenos con condiciones superiores al promedio, aunque contaban con algún tipo de declives o pendientes. El estado general de los aparatos en estudio era inferior o igual a regular, y se ve afectado por los desechos, la falta de basureros e iluminación, la altura del césped, la falta de agua para hidratar a la población y la carencia de desagües. Asimismo, los tres daños más frecuentes que sufrían los aparatos y otras estructuras eran la herrumbre, el despintado y los aparatos dañados, aspectos que deterioraban las infraestructuras y hacían los campos de juegos lugares poco atractivos para su utilización.

El mantenimiento en los campos de juego era escaso y lo que se realiza es la corta de césped y esporádicamente la soldadura de aparatos dañados. Este mantenimiento se brindaba una vez al mes y en otros casos cada tres meses, cuando las comunidades contaban con fondos o ante las denuncias o llamadas a la Municipalidad. En la mayoría de los casos, el mantenimiento lo brindaba la propia comunidad por medio de grupos, juntas o asociaciones, o en su efecto la Municipalidad cuando respondía a las denuncias, llamadas o solicitudes de las comunidades. Además, la mayoría de las agrupaciones que brindaba el mantenimiento a los campos de juego no contaba con un plan de mantenimiento que facilitara la atención y necesidades que con el tiempo, el uso y el clima sufren los campos de juego.

Con respecto al nivel de seguridad se concluye que los campos de juego en su mayoría estaban abiertos a la población pero no todos contaban con malla de protección que diera seguridad a dichas estructuras. Además, estos espacios no poseían reglamentos, señalamientos o letreros que orientaran a las personas visitantes en su utilización. Los peligros en estas estructuras eran notables (la corrosión, las puntas filosas y los aparatos rotos o dañados) y se presentaban con frecuencia en los aparatos y otras estructuras. A pesar de que las superficies encontradas eran variadas (el césped, la tierra dura y la combinación de tierra dura y césped), estas eran superficies poco seguras para la población que los utilizaba.

Asimismo, se concluye que no solo la infraestructura y la administración eran factores que podrían determinar el estado estructural y seguridad de los campos de juego en este estudio, puesto que las condiciones socioeconómicas y el 
nivel educativo podrían también influir en el estado estructural y administrativo de los campos de juego en estudio. Los campos de juego deben existir por ley en las urbanizaciones, residenciales y las comunidades y deben ser debidamente equipados por los urbanizadores o en su efecto por la Municipalidad. Ambas normas legislativas se estaban incumpliendo.

Una vez finalizada esta investigación y al evidenciar las condiciones tan preocupantes en que se encuentran los campos de juegos en el cantón central de Heredia en todos los aspectos (infraestructura, mantenimiento y seguridad), la autora elaboró una guía para orientar a la población usuaria en el mejoramiento de estos espacios lúdicos que, por ley, otorga el gobierno al uso de las comunidades. Esta guía se elaboro con el fin de educar, orientar, facilitar y motivar a las personas en el rescate de espacios tan valiosos que hoy están en el olvido y que hoy en día pueden ser una herramienta que contribuya a combatir los problemas de salud de la población nacional, especialmente la infantil.

También, luego de finalizar esta investigación, se palpó la necesidad e interés que presentó la comunidad herediana acerca de los campos de juego, por lo que es importante iniciar un plan de capacitaciones no solo en el cantón Central sino en todo el país para un mejor aprovechamiento de este recurso. Además, es de suma importancia el fomentar la participación comunitaria en el mantenimiento de los campos de juego, ya que la comunidad es la base para que estos espacios se conserven y utilicen de manera adecuada, con el fin de profundizar más en aspectos socioeconómicos y sociodemográficos de las comunidades.

Por lo tanto, se recomienda que para el diseño, la planificación y el mejoramiento de los campos de juego se tomen en cuenta la edad, el sexo, el contexto geográfico y la población a la cual va dirigido. Este análisis del estado estructural y administrativo de los campos de juego es útil para futuros estudios en el campo de la recreación y los espacios recreativos y confirma, a su vez, las condiciones reales en que se encuentran estos espacios lúdicos. Al mismo tiempo, esta investigación se puede utilizar como plan piloto, con el fin de implementarlo en otras zonas de la provincia o del resto del país.

Para futuros estudios, se recomienda utilizar la entrevista semi-estructurada como instrumento para indagar sobre el mantenimiento que el grupo responsable le da a los campos de juego. Así mismo, se sugiere considerar los campos de juego existentes en centros educativos públicos y privados, instituciones o centros públicos y privados, para establecer una comparación en el mantenimiento, la administración y la seguridad que estos reciben. A su vez, se recomienda estudiar la utilización y edad de las personas usuarias de estos espacios recreativos, así como el grado de satisfacción obtenido por ellas; además, considerar las causas del deterioro de las estructuras y aparatos y el tipo de utilización que se les dé a estos espacios. Es imprescindible revisar, cambiar, actualizar y establecer regulaciones a la legislación nacional que actualmente rige los campos de juego, ya que esta es escasa, en algunos casos poco clara y no contempla muchos aspectos de infraestructura, seguridad y mantenimiento necesarios para que ellos reúnan las condiciones óptimas para su utilización. Es importante considerar la continuidad de este estudio mediante la confección de una guía de uso y la identificación de los beneficios que cada aparato aporta en el desarrollo integral de las personas usuarias.

\section{Notas}

1 Durante la recolección de datos de esta investigación la autora era estudiante de maestría de la Universidad de Costa Rica.

2 Mantenimiento: conservar una cosa en su ser y estado, para lograr darle vigor y permanencia (La Enciclopedia Volumen XIII, 2004). 
3 Seguridad: ciertos mecanismos que aseguran el buen funcionamiento y previenen que este falle, se frustre o se violente (La Enciclopedia Volumen $\mathrm{XV}, 2004)$.

4 Infraestructura: conjunto de elementos o servicios que se consideran necesarios para la creación, destinados a facilitar el funcionamiento del campo de juego (La Enciclopedia Volumen XI, 2004).

5 Estado estructural: situación en que se encuentra una cosa y en especial cada una de las condiciones de los elementos que la componen, los cuales están sujetos a cambios (La Enciclopedia Volumen V, 2004).

6 Administrativo: es el proceso de trabajar con las personas y con los recursos para lograr las metas de la organización (Bateman y Snell, 2004).

7 Mejoramiento: acción y efecto de mejorar: poner en lugar, condición o grado ventajoso al que antes se tenía (La Enciclopedia Volumen XIII, 2004).

8 Aprovechamiento: acción y efecto de aprovechar, emplear y sacar utilidad de alguna cosa que aparentemente carece de ella (La Enciclopedia Volumen II, 2004).

\section{Referencias bibliográficas}

Acic, Y., Gulbayrak, C. y Turaci, G. (2004). Investigation of the level of safety and appropriateness of playgrounds in Elazing city in Turkey. International Journal Enviroment Health Resistence, 14(1), 75-82. Obtenido el 10 de febrero del 2005, de: http:// www.ncbi.nlm.nih.gov/entrez/query.f cgi?cmd=pubmed\&dopt=Abstract\&li st_uids $=14660120$

Asamblea General de las Naciones Unidas. (1948). Declaración universal de los derechos humanos. Obtenido el 17 de mayo del 2005 de http://www.org/ spanish/aboutun/hrights.htm

Bateman, T. y Snell, S. (2004). Administración, una ventaja competitiva (4⿳亠丷厂 ed.). México: McGraw-Hill.
Bird, W. (2007). Natural fit: Can green space and biodiversity increase levels of physical activity? (A report by Royal Society for the Protection of Birds). Obtenido el 4 de octubre del 2010, de: http://www.rspb.org.uk/ Images/natural_fit_full_version_ tcm9-133055.pdf

Blumenau, K., Rovira-Beleta, E. y Cuyás, E. (1996). Deporte y documentación No. 27: Instalaciones deportivas sin barreras. Málaga, España: Instituto Andaluz del Deporte.

Booth, N. (1988). Playgrounds: Safety and fun by design. Parks and Recreation, 23(10), 28-32.

Butler, G. (1966). Principios y métodos de recreación para la comunidad. Argentina: Bibliográfica Omega.

Cavnar, M., Kirtlanda, K., Evans, M., Wilson, D., Williams, J., Mixon, G., y Henderson, K. (2003). Recreation facility evaluation instrument. Prevention Research Center, Arnold School of Public Health, University of South Carolina. Recuperado el 12 de diciembre del 2005, de http://prevention.shp.sc.edu/tools/ RecFacilityTool.pdf

Christiansen, M. (2002). Playground maintenance needs assessment: Initial steps to maintain child's play. Parks and Recreation, 37(4), 15-31.

Costa Rica. Asamblea Legislativa, Leyes vigentes por nombre de la ley. (1978). Ley Núm. 4240 Planificación Urbana. Obtenido el 14 de mayo del 2005, de http://asamblea.racsa.co.cr/ley/leyes_ nombre.htm

Costa Rica. Instituto Nacional de Vivienda y Urbanismo [INVU]. (1982). Reglamento para el control nacional 
de fraccionamientos y urbanizaciones. Obtenido el 19 de abril de 2006, de: http://www.mivah.go.cr/Leyes $\% 20$ y $\% 20$ decretos/Reglamento $\% 20$ fraccionamiento.pdf

Costa Rica. Tribunal Supremo de Elecciones. (1949). Constitución política de la República de Costa Rica. Obtenido el 1ro de abril de 2006 de http://www. tse.go.cr/consti.html

Craig, R., Mindell, J. y Hirani, V. (eds.). (2009). Health survey for England 2008: Physical activity and fitness. Volume 1: Physical activity and fitness. London: NHS Information Centre for Health and Social Care.

Ewert, A. y Plumb, S. (1999). Physical resourses management. En B. Van der Smissen, M. Moiseichik, V. Hartengurg, y L. Twardzik. (Eds.), Management of parks and recreation agencies (pp. 295-359). Ashburn, VA: National Recreation and Parks Association.

Fondo de Población de las Naciones Unidas [UNFPA] y el Consejo de la Persona Joven. (2002). Ley Núm. 8261 General de la persona joven. San José, Costa Rica: Lara Segura \& Asoc.

Fondo Internacional de Emergencia de las Naciones Unidas para la Infancia [UNICEF] y Defensoría de los Habitantes. (1998). Código de la niñez y la adolescencia. San José, Costa Rica: UNICEF.

Frost, J., Sutterby, J., Therrell, J., Brown, P. y Thornton, C. (2002). Does height matter? Parks and Recreation, 37(4), 74-83.

Galera, A. y Llusá, J. (1996). Cuaderno técnico del deporte No. 26: Gestión del material y mantenimiento de las instalaciones deportivas. Málaga, España: Instituto Andaluz del Deporte.

Gallahue, D. y Vannier, M. (1978). Teaching physical education in elementry schools. Philadelphia, Estados Unidos: W.B. Saunders Co.

García, M. (2001). El juego es el mejor juguete. Revista del consumidor, 298. Recuperado el 3 de febrero del 2005 de http://www.profeco.gob.mx/html/ revista\%5Cpdf\%5Cvjuguete 2001 . pdf\#search='patio\%20de\%20recreo'

Gómez, M. (1990). Elementos de estadística descriptiva. San José, Costa Rica: EUNED.

Hernández, R., Fernández, C. y Baptista, P. (2003). Metodología de la investigación (3a ed.). México: McGraw-Hill/ Interamericana S.A.

Hinkley, T., Crawford, D., Salmon, J., Okely, A. D. y Hesket, K. (2008). Preschool children and physical activity: A review of correlates. American Journal of Preventive Medicine, 34(5), 435-441.

Horning, E. (2005). Brinding family back to the park. Parks and Recreation, 40(7), 47-51.

Hudson, S., Mack, M. y Thompson, D. (2000). Play is safe. Steps to keeping playground surfacing safe for our children. Parks and Recreation, 35(4), 78-85.

Hudson, S., Mack, M. y Thompson, D. (2002). Signs of the times. Parks and Recreation, 37(4), 60-65.

Hudson, S., Thompson, D. y Olsen, H. (2004). How safe are ours playgrounds? Parks and Recreation, 39(4), 53-59. 
Hudson, S. y Thompson, D. (2001). Are playgrounds still viable in the 21st century? Parks and Recreation, 36(4), 54-62.

Kilitzus, H., Meuli, R., Jank, W., Scheurer, H. y Léchot, F. (1996). Deporte y documentación No. 28: Revestimientos y suelos parainstalaciones deportivas. Málaga, España: Instituto Andaluz del Deporte.

Kraus, R. y Curtis, J. (2000). Creative management in recreation, parks and leisure services ( $6^{\mathrm{a}}$ ed.). USA: McGraw-Hill Campanies, Inc.

Kutska, K. (2001). Playground maintenance or inspection, which comes first? Parks and Recreation, 36(4), 92-107.

La Enciclopedia. (2004). Madrid: Salvat Editores.

Lépiz, O. y Jiménez, S. (2000). Una oportunidad para la igualdad: Comentario a la ley 7600 sobre la igualdad de oportunidades para las personas con discapacidad. Costa Rica: Gossestra S.A.

Lillis, K. y Jaffe, D. (1997). Playground injuries in children. Pediatric Emergence Care, 13(2), 149-153. Obtenido el 12 de febrero del 2005 de http://www. ncbi.nlm.nih.gov/entrez/query.fcgi?c $\mathrm{md}=$ Retrieve $\& \mathrm{db}+$ pudmed $\& \mathrm{dopt}=\mathrm{Ab}$ stract\&list_uids $=9127428$

López, M. y Estapé, E. (2002). La zona de juegos, un espacio para la educación física en los centros escolares. Revista Digital Efdeportes Buenos Aires, 53(8). Recuperado el 3 de febrero del 2005, de http://efdeportes.com/

Miles, L. (2007). Physical activity and health. Nutrition Bulletin, 32(4), 314363.
O'Brien, E. (1998). Playground safety: It is everybody responsability. Parks and Recreation, 33(4), 2.

Paredes, J. (2003). Juego, luego soy: Teoría de la actividad lúdica. Sevilla, España: Wanceulen Editorial Deportiva, S.L.

Parker, D. (2000). Checkin' it twice: Playground maintenance is crucial for safe areas for child's play. Parks and Recreation, 35(4), 96-99.

Pavía, V., Lorente, M., Quinteros, N. y Verbic, F. (2002). El derecho al juego. Revista Digital Efdeportes Buenos Aires, 51(8). Recuperado el 3 de febrero del 2005 de http://efdeportes.com/efd51/juego.htm

Peterson, J. (2002). Eliminate playgrounds, you must be nuts! Parks and Recreation, 37(4), 92-95.

Petrido, E., Silbert, J., Dedoukou, X., Skalkidis, I. y Trichopoulos, D. (2002). Injuries in public and private playgrounds: The relative contribution of structural, equipment and human factors. Revista Digital PudMed, 91(6), 691-697. Obtenido el 17 de febrero del 2005 de: http:// www.ncbi.nlm.nih.gov/entrez/query.f cgi?cmd=Retrieve\&db=pubmed\&dop $\mathrm{t}=$ Absract\&list_uids $=12162604$

Rico, C. (2002, 22-25 junio). Del espacio público al espacio lúdico: el papel de la Recreación en la construcción de lugares. Ponencia presentada en el Panel "El espacio público como generador de usos alternativos para la convivencia ciudadana en torno a la Recreación”, en III Foro Internacional de Parques. Bogotá, Colobmia. Recuperado el 3 de febrero del 2005, de http://www.redcreación. org/articulos/espaciopublico_ espacioludico.html 
Salazar, C. G. (2002). Core competencies and affective characteristics for an undergraduate general curriculum in recreation and leisure services. Tesis doctoral no publicada, Indiana University, Bloomington, USA.

Salazar, C. G. (2006a). Inspección de un parque de juego de niños ("playgrounds”). Curso EF-0024 Recreación y Juegos Organizados, Escuela Educación Física y Deportes, Universidad de Costa Rica. San José, C, R. Manuscrito sin publicar.

Salazar, C. G. (2006b). Lista de chequeo para supervisión de parques de juego "playgrounds". Curso EF-0024 Recreación y Juegos Organizados, Esc. Educación Física y Deportes, Universidad de Costa Rica. Costa Rica: Autora.

Sallis, J. F., Prochaska, J. J. y Taylor, W. C. (2000). A review of correlates of physical activity and adolescents. Medicine and Science in Sports and Exercise, 32(5), 963-975.

Spinks, A., Macpherson, A., Bain, C. y McClure, R. (2006). Determinants of sufficient daily activity in Australian primary school children. Journal of Paediatrics \& Child Health, 42(11), 674-679.

Stillwell, J.(1987). Makingandusingcreative play equipment. Estados Unidos: Human Kinestics Publishers.

van Sluijs, E. M. F., McMinn, A. M. y Griffin, S. J. (2007). Effectiveness of interventions to promote physical activity in children and adolescents: Systematic review of controlled trials. British Medical Journal, 335, 703-707.

Wadell, K. (2001). What is the minimum standard of care that the playground owner must provide? Parks and Recreation, 36(4), 80-86.

Willenberg, L. K., Ashbolt, R., Holland, D., Gibbs, L., MacDougall, C., Garrard, J., Green, J. B. y Waters, E. (2009). Increasing school playground physical activity: A mixed methods study combining environmental measures and children's perspectives. Journal of Science and Medicine, 13(20), 210-216. 